( ) Copyright 2014 American Meteorological Society (AMS). For permission to reuse any portion of this work, please contact permissions@ametsoc.org. Any use of material in this work that is determined to be "fair use" under Section 107 of the U.S. Copyright Act (17 U.S. Code §?107) or that satisfies the conditions specified in Section 108 of the U.S. Copyright Act (17 USC § 108) does not require the AMS's permission. Republication, systematic reproduction, posting in electronic form, such as on a website or in a searchable database, or other uses of this material, except as exempted by the above statement, requires written permission or a license from the AMS. All AMS journals and monograph publications are registered with the Copyright Clearance Center (https://www.copyright.com). Additional details are provided in the AMS Copyright Policy statement, available on the AMS website (https://www.ametsoc.org/PUBSCopyrightPolicy).

\title{
Synoptic Typing and Precursors of Heavy Warm-Season Precipitation Events at Montreal, Québec
}

\author{
Shawn M. Milrad, * Eyad H. Atallah, John R. Gyakum, and Giselle Dookhie ${ }^{+}$ \\ Department of Atmospheric and Oceanic Sciences, McGill University, Montreal, Quebéc, Canada
}

(Manuscript received 26 February 2013, in final form 12 November 2013)

\begin{abstract}
A precipitation climatology is compiled for warm-season events at Montreal, Québec, Canada, using 6-h precipitation data. A total of 1663 events are recorded and partitioned into three intensity categories (heavy, moderate, and light), based on percentile ranges. Heavy (top 10\%) precipitation events $(n=166)$ are partitioned into four types, using a unique manual synoptic typing based on the divergence of $\mathbf{Q}$-vector components. Type A is related to cyclones and strong synoptic-scale quasigeostrophic (QG) forcing for ascent, with high- $\theta_{e}$ air being advected into the Montreal region from the south. Types B and C are dominated by frontogenesis (mesoscale QG forcing for ascent). Specifically, type B events are warm frontal and feature a near-surface temperature inversion, while type $\mathrm{C}$ events are cold frontal and associated with the largest-amplitude synoptic-scale precursors of any type. Finally, type D events are associated with little synoptic or mesoscale QG forcing for ascent and, thus, are deemed to be convective events triggered by weak shortwave vorticity maxima moving through a long-wave ridge environment, in the presence of an anomalously warm, humid, and unstable air mass that is conducive to convection. In general, types A and B feature the strongest dynamical forcing for ascent, while types $\mathrm{C}$ and $\mathrm{D}$ feature the lowest atmospheric stability. Systematic higher precipitation amounts are not preferential to any event type, although a handful of the largest warm-season precipitation events appear to be slow-moving type $\mathrm{C}$ (stationary front) cases.
\end{abstract}

\section{Introduction}

\section{a. Motivation}

Quantitative precipitation forecasts (QPFs) remain an important challenge in meteorology, especially during heavy precipitation events (Sisson and Gyakum 2004; Milrad et al. 2009b). Roebber and Bosart (1998) and Sisson and Gyakum (2004) pointed out that while forecast skill of mass fields (e.g., 500-hPa height) has improved greatly, QPF skill lags behind. As shown by the National Oceanic and Atmospheric Administration (NOAA) Weather Prediction Center QPF verification,

* Current affiliation: Department of Applied Aviation Sciences, Embry-Riddle Aeronautical University, Daytona Beach, Florida.

${ }^{+}$Current affiliation: Meteorological Service of Canada, Edmonton, Alberta, Canada.

Corresponding author address: Shawn M. Milrad, Dept. of Atmospheric and Oceanic Sciences, McGill University, Room 945, Burnside Hall, 805 Sherbrooke Street West, Montreal QC H3A 0B9, Canada. E-mail: shawn.milrad@gmail.com human QPFs (ostensibly based on mass fields) can still outperform model QPFs by $30 \%-40 \%$ (information online at http://www.hpc.ncep.noaa.gov/images/hpcvrf/ 1inQPFImpann.gif). This is particularly true during the warm season, when convective precipitation is often responsible for substantial flooding (Fritsch and Carbone 2004; Heideman and Fritsch 1988). As such, a greater understanding of mass field precursors and characteristics of heavy precipitation events can lead to increased human QPF skill.

Previous studies have examined synoptic-scale precursors and characteristics of cool-season heavy precipitation events, including Lackmann and Gyakum (1996) and Roberge et al. (2009) for the Northwest Territories of Canada; Lackmann and Gyakum (1999) and Warner et al. (2012) for the U.S. Pacific Northwest; Sisson and Gyakum (2004) for Burlington, Vermont; Martius et al. (2008) for the Alps; and Milrad et al. (2009b, 2010b) for Atlantic Canada. For example, Lackmann and Gyakum $(1996,1999)$ and Roberge et al. (2009) found that heavy cool-season precipitation events in western North America often involved substantial moisture transport [atmospheric 
rivers, e.g., Ralph et al. (2004)] from the subtropics. Milrad et al. (2009b, 2010b) revealed that mass field precursors (e.g., 500-hPa troughs) of heavy precipitation events at St. John's, Newfoundland, were often visible in the central United States up to 3 days prior to the event, and that moisture transport from both the Gulf and Atlantic was important in producing large amounts of precipitation. Additional synoptic-scale insight (e.g., the role of jet streaks, diabatic heating, etc.) into extreme precipitation events has been gained through case studies of historic storms, for example, the Presidents' Day storm (Bosart 1981), the QE II storm (Gyakum 1991), the 1993 Superstorm (Bosart et al. 1996), and the 1998 Ice Storm (Gyakum and Roebber 2001; Roebber and Gyakum 2003).

Previous work has shown that at least $50 \%$ of warmseason precipitation in the United States is associated with mesoscale processes (Heideman and Fritsch 1988; Schumacher and Johnson 2006). Classifications and causal mechanisms of heavy warm-season precipitation events in the United States have been documented by Maddox et al. (1979), Heideman and Fritsch (1988), Funk (1991), LaPenta et al. (1995), Konrad (1997), and Gyakum et al. (2005). Notably, only one of those studies (Gyakum et al. 2005) utilized modern reanalysis datasets, which dwarf older methods (e.g., objective analyses of twice-daily soundings) in spatial and temporal resolution. More recently, Schumacher and Johnson (2005, $2006,2008,2009)$ looked at mesoscale factors in extreme warm-season rainfall and flash flood events in the United States. Schumacher and Johnson (2006) found that nearly all extreme warm-season rainfall events in the northern United States were associated with mesoscale convective systems (MCSs), while cool-season extreme events were dominated by strong synoptic-scale forcing.

In Canada, research into heavy precipitation events has been largely limited to case studies such as the 1996 Montreal flood (Durnford 2001), consecutive extreme events at St. John's (Milrad et al. 2010a), and the droughtbreaking Canadian prairie rainstorm of 2002 (Szeto et al. 2011). In addition, the Canadian Atlantic Storms Program (CASP) I and II field projects examined the formation of heavy mesoscale precipitation bands and the role of latent heat release in cyclone development (e.g., Stewart et al. 1987; Stewart and Donaldson 1989; Gyakum and Stewart 1996; Gyakum et al. 1996). Studies that have explored composite synoptic-scale precursors and structures have focused on coastal regions during the cool season (e.g., Lackmann and Gyakum 1996; Milrad et al. 2009b; Milrad et al. 2010b). However, there are positive secular trends in precipitation amount and frequency during summer (Stone et al. 2000), including in southern Quebéc (Yagouti et al. 2008), signifying that understanding the dynamic

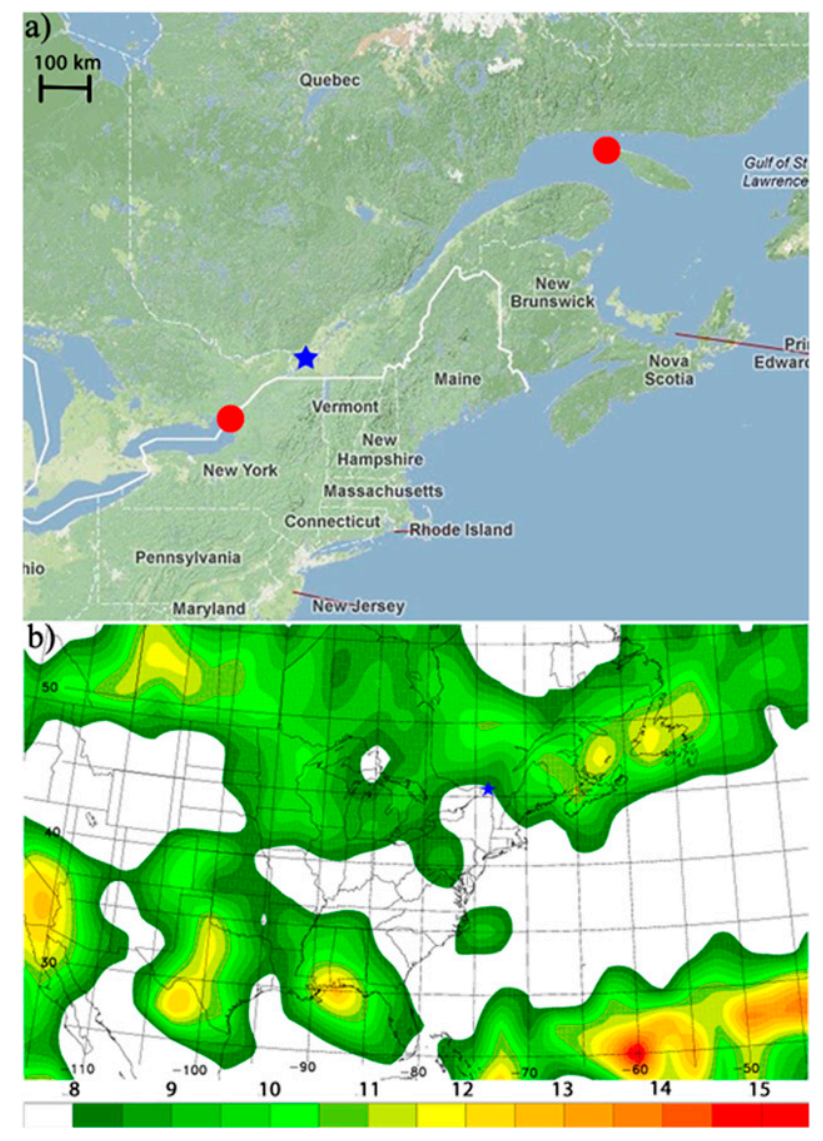

FIG. 1. (a) Map of the SLRV and the area surrounding Montreal. (b) June-November frequency of 500-hPa absolute vorticity centers based on a 30-yr (1979-2008) climatology from the NCEPNCAR reanalysis, calculated by counting the number of absolute vorticity maxima in the region shown; this roughly depicts the mean North American storm tracks and their importance to the Montreal region. The units are numbers of events per $5^{\circ} \times 5^{\circ}$ area (approximately $500 \mathrm{~km}^{2}$ ). For reference, CYUL is marked with a blue star in both panels and the red dots in (a) mark the endpoints of the SLRV.

and thermodynamic characteristics of heavy precipitation events is particularly important within the context of climate change.

\section{b. Objectives}

This study explores the synoptic-scale precursors and characteristics of warm-season precipitation events at Montreal, Québec, Canada (CYUL). Montreal is located in the St. Lawrence River valley (SLRV), which runs southwest-northeast through eastern Ontario and Québec (Fig. 1a), and is home to the majority of the population in the province of Québec. Heavy warm-season precipitation events (and resulting flash flooding) can have a large impact on life and property in the region (Durnford 2001), as Montreal is located in an active warm-season 
storm-track region. Figure $1 \mathrm{~b}$ displays the $500-\mathrm{hPa}$ absolute vorticity frequency, compiled using an automated technique that counted absolute vorticity maxima over a 30-yr period (1979-2008) from the National Centers for Environmental Prediction-National Centers for Atmospheric Research (NCEP-NCAR) global reanalysis (Kalnay et al. 1996). In Fig. 1b, frequency maxima are observed both to the west (Great Lakes) and east (Atlantic Canada) of Montreal during the warm season, consistent with the average position of the jet stream and common storm tracks (Zishka and Smith 1980).

For this study, we chose the months of June-November for the years 1979-2008. The time period was chosen to correspond with the Atlantic basin tropical cyclone (TC) season (1 June-30 November), because past research has indicated that tropical cyclones that are undergoing or have undergone extratropical transition (ET) can impact the Montreal region with heavy precipitation (e.g., Hart and Evans 2001; Milrad et al. 2009a; Milrad et al. 2013). Some notable recent cases include the ETs of Hurricanes Ike (2008) and Irene (2011) (Milrad et al. 2009a; Milrad et al. 2013). Furthermore, even when the center of the TC or remnant TC is far from the region of interest, heavy precipitation events can sometimes occur well ahead of the TC. These predecessor rain events (PREs, e.g., Galarneau et al. 2010; Schumacher and Galarneau 2012; Moore et al. 2013) occur when a preexisting midlatitude trough or frontal boundary helps to draw tropical moisture from the TC northward, resulting in heavy precipitation well in advance of the TC itself. PREs have been previously identified as the cause of several heavy warm-season precipitation events in eastern Canada, for example, prior to the ET of Hurricane Juan (2003) (Milrad et al. 2009a).

Once we have identified our warm-season precipitation events, our objectives are to

- assemble a warm-season precipitation event climatology and partition events into three intensity categories based on percentile ranges (heavy, moderate, and light);

- complete a manual dynamically based synoptic typing of heavy precipitation events, based on Dookhie (2011), and motivated by observed composite smearing that results in "washed out" synoptic-scale features when all heavy precipitation events are composited together; and

- compare and contrast the synoptic-scale precursors and characteristics of the various types of heavy precipitation events, elucidating important features.

Section 2 details the data used and section 3 describes the precipitation climatology and our synoptic typing methodology for heavy events. Section 4 details the synoptic-dynamic analysis for each type of heavy event.
Finally, section 5 presents conclusions and avenues of future work.

\section{Data}

Six-hourly precipitation data for Montreal's Pierre Elliot Trudeau International Airport (CYUL; Fig. 1) were obtained from Environment Canada. These data were acquired through the Data Access Integration (DAI) online catalog (Ouranos 2012; online at http:// loki.qc.ec.gc.ca/DAI/), and have been corrected for inhomogeneities and systematic biases (e.g., gauge errors from wind), as well as being adjusted for changes in instrumentation and measurement procedures (Mekis and Hogg 1999).

For the synoptic-dynamic analysis, we used the NCEP-Department of Energy Atmospheric Model Intercomparison Project (AMIP-II) reanalysis (R2; Kanamitsu et al. 2002), updated from the original NCEPNCAR global reanalysis (Kalnay et al. 1996). This dataset has global coverage, a spatial resolution of $2.5^{\circ} \times$ $2.5^{\circ}$, a temporal resolution of $6 \mathrm{~h}$, and is available from 1979 to the present. Our results were checked for consistency using the NCEP North American Regional Reanalysis (NARR; Mesinger et al. 2006), which has a $32-\mathrm{km}$ grid spacing and a temporal resolution of $3 \mathrm{~h}$, available from 1979 to the present, and the NCEP Climate Forecast System Reanalysis (CFSR; Saha et al. 2010), which has a $0.5^{\circ}$ grid spacing and a temporal resolution of $6 \mathrm{~h}$, and is also available from 1979 to the present. For synoptic-scale features, the results from R2, NARR, and CFSR were found to be very similar. The backward-trajectory analysis was completed with NCEP-NCAR reanalysis (Kalnay et al. 1996) data using the NOAA/Air Resources Library (ARL) Hybrid Single Particle Lagrangian Integrated Trajectory (HYSPLIT) model (Draxler and Rolph 2012, http://ready. arl.noaa.gov/HYSPLIT_traj.php). Analyses are displayed using the General Meteorological Package (GEMPAK) version 6.2.0, updated from the original software devised by Koch et al. (1983).

Throughout the paper, $t=0 \mathrm{~h}$ is defined throughout as the start of the heaviest 6 -h precipitation period at CYUL. Composite anomalies are computed with respect to a monthly weighted 30-yr (1979-2008) climatology derived from $\mathrm{R} 2$.

\section{Warm-season precipitation events}

\section{a. Event selection and precipitation climatology}

Following Milrad et al. (2009b), precipitation events are defined as consecutive periods of precipitation, ranging from as few as one recording period $(6 \mathrm{~h})$ to as many as 


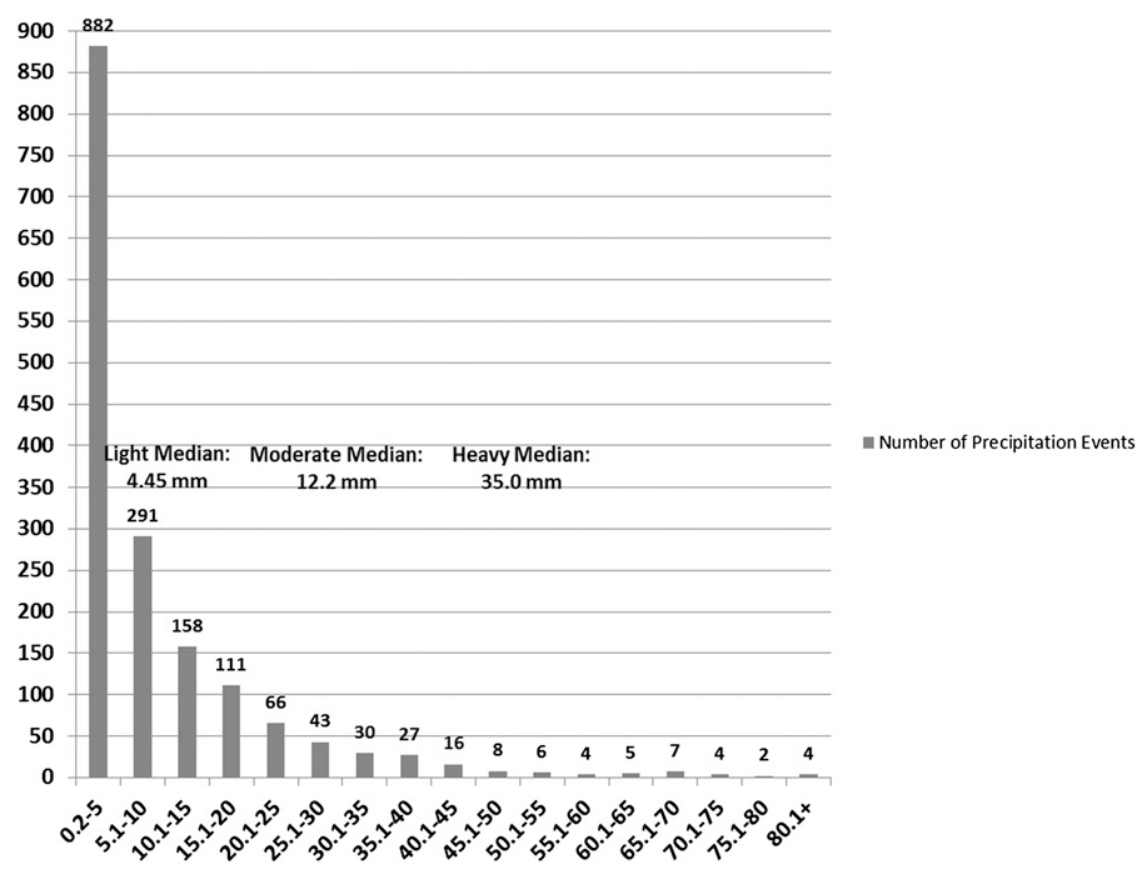

FIG. 2. The overall precipitation event distribution histogram depicting bins for every $5 \mathrm{~mm}$ with the number of events in each bin written above each bar. The median of each precipitation category (heavy, 90th-100th percentile; moderate, 70th-80th percentile; light, 45 th-55th percentile) is also indicated.

12 (72 h). Precipitation periods exceeding $72 \mathrm{~h}$ are deemed to consist of multiple synoptic-scale events that could not be objectively separated. To ensure event separation, there are no fewer than two recording periods $(12 \mathrm{~h})$ of zero precipitation (Milrad et al. 2009b) between events.

In all, 1663 warm-season precipitation events $(\geq 0.2 \mathrm{~mm})$ are identified. Figure 2 shows the event distribution, binned by precipitation amount. As noted by Milrad et al. (2009b), precipitation event distributions are typically skewed toward lighter events (Fig. 2). Here, we define heavy events as the top $10 \%$ of precipitation events (90th-100th percentile), moderate events as the 70th-80th percentile range, and light events as the 45th55 th percentile range (Table 1 ). These ranges are merely selected to ensure proper separation with respect to intensity; we tested the use of slightly different ranges (e.g., 85th-95th percentile for heavy events), and our composite results did not change substantively.

Following Sisson and Gyakum (2004) and Milrad et al. (2009b), we calculated the median precipitation amount for each category (Table 1). We subsequently took 25 events above and 25 events below the median precipitation amount to compose the 50 median events for each category (Sisson and Gyakum 2004; Milrad et al. 2009b).

A composite analysis of the 50 median events in each event category (not shown here for the sake of brevity) generally showed a more southern storm track and stronger synoptic-scale features in the heavy cases, similar to results from previous cool-season studies (e.g., Milrad et al. 2009b). However, there was notable composite smearing in the heavy cases, such that a synoptic typing and more detailed analysis of these events are warranted. Thus, we focus on the heavy (top $10 \%$ ) events for the remainder of the paper. Detailed comparisons between different intensity classes of precipitation (e.g., heavy versus moderate) are left for future work.

\section{b. Partitioning methodology}

Manual synoptic typing has been used for surface and upper-air analyses of weather events in west Texas (Ladd and Driscoll 1980), an environmental baseline and air quality analysis in Louisiana (Muller 1977; Muller and Jackson 1985), a synoptic climatology for the Gulf of

TABLE 1. Precipitation amount and percentile ranges for heavy, moderate, and light events.

\begin{tabular}{llcc}
\hline $\begin{array}{c}\text { Event } \\
\text { class }\end{array}$ & $\begin{array}{c}\text { Percentile } \\
\text { range }\end{array}$ & $\begin{array}{c}\text { Precipitation } \\
\text { amount } \\
\text { range }(\mathrm{mm})\end{array}$ & $\begin{array}{c}\text { Median } \\
\text { precipitation } \\
\text { amount }(\mathrm{mm})\end{array}$ \\
\hline Heavy & 90th-100th & $24.1-134.5$ & 35.0 \\
Moderate & 70th-80th & $10-15$ & 12.2 \\
Light & 45th-55th & $3.5-5.5$ & 4.45 \\
\hline
\end{tabular}


Alaska (Overland and Hiester 1980), and, more recently, extreme cool-season precipitation events in Atlantic Canada (Milrad et al. 2010b). In addition, Maddox et al. (1979) devised a classification scheme for nontropical warm-season precipitation events that separated events into three categories: synoptic (cyclone), frontal, and convective (outflow boundaries). LaPenta et al. (1995) subsequently used a similar classification scheme for extreme warm-season precipitation events; their categories were tropical cyclone (T), extratropical cyclone (E), stationary cold front (S), and unknown (U).

With previous classification systems in mind, we build on the partitioning scheme of Dookhie (2011), which utilized threshold values of dynamical forcing for ascent. First, we present the Q-vector form of the inviscid, adiabatic quasigeostrophic (QG) omega equation:

$$
\left(\nabla_{p}^{2}+\frac{f_{o}^{2}}{\sigma} \frac{\partial^{2}}{\partial p^{2}}\right) \omega=-2 \nabla_{p} \cdot \mathbf{Q},
$$

where $f_{o}$ is the constant Coriolis parameter $\left(\mathrm{s}^{-1}\right), \sigma$ is the static stability parameter $\left(\mathrm{m}^{2} \mathrm{~s}^{-2} \mathrm{~Pa}^{-2}\right), \omega$ is the vertical velocity $\left(\mathrm{Pa} \mathrm{s}^{-1}\right)$, and the sense of the vertical motion is related to the divergence of the $\mathbf{Q}$ vector, $\mathbf{Q}$. This was expressed by Hoskins et al. (1978): "in quasi-geostrophic theory. . .vertical velocity is forced solely by the divergence of Q.” In other words, areas of $\mathbf{Q}$-vector convergence are associated with QG ascent.

We subsequently separate the $\mathbf{Q}$ vector into its alongisentrope $\left(\mathbf{Q}_{s}\right)$ and across-isentrope $\left(\mathbf{Q}_{n}\right)$ components, originally devised by Keyser et al. (1988) and later discussed by Martin $(2006 a, b)$ :

$$
\begin{aligned}
\mathbf{Q}_{s} & =\left[\frac{\mathbf{Q} \cdot(\mathbf{k} \times \nabla \theta)}{|\nabla \theta|}\right] \frac{\mathbf{k} \times \nabla \theta}{|\nabla \theta|} \text { and } \\
\mathbf{Q}_{n} & =\left(\frac{\mathbf{Q} \cdot \nabla \theta}{|\nabla \theta|}\right) \frac{\nabla \theta}{|\nabla \theta|} .
\end{aligned}
$$

Keyser et al. (1988), Martin (2006a,b), and Milrad et al. (2010a) pointed out that $\mathbf{Q}_{s}$ convergence $\left(\nabla_{p} \cdot \mathbf{Q}_{s}<0\right)$ is representative of synoptic-scale forcing for ascent, while $\mathbf{Q}_{n}$ convergence $\left(\boldsymbol{\nabla}_{p} \cdot \mathbf{Q}_{n}<0\right)$ is representative of mesoscale forcing for ascent. In relation to other commonly used forms (e.g., traditional, Sutcliffe-Trenberth) of the QG omega equation (Bluestein 1992), $\mathbf{Q}_{s}$ convergence is generally representative of cyclonic vorticity advection (CVA) by the thermal wind [i.e., the combination of differential CVA and geostrophic warm-air advection (WAA)], while $\mathbf{Q}_{n}$ convergence is associated with geostrophic frontogenesis (Keyser et al. 1988; Martin 2006a,b).

We note that $\mathbf{Q}$-vector divergence fields (and therefore $\mathbf{Q}_{s}$ and $\mathbf{Q}_{n}$ divergence) are generally noisy fields, especially
TABLE 2. Characteristics of each heavy event type as used for the manual synoptic typing. Negative values represent $\mathbf{Q}$-vector convergence, indicative of ascent.

\begin{tabular}{llcc}
\hline \hline \multicolumn{1}{c}{ Type } & Description & $\begin{array}{c}\nabla_{p} \cdot \mathbf{Q}_{s}\left(\times 10^{-17}\right. \\
\left.\mathrm{K} \mathrm{m}^{-2} \mathrm{~s}^{-1}\right)\end{array}$ & $\begin{array}{c}\nabla_{p} \cdot \mathbf{Q}_{n}\left(\times 10^{-17}\right. \\
\left.\mathrm{K} \mathrm{m}^{-2} \mathrm{~s}^{-1}\right)\end{array}$ \\
\hline $\mathrm{A}(n=103)$ & Cyclone & $<0$ & $\left|\nabla_{p} \cdot \mathbf{Q}_{n}\right|<\left|\nabla_{p} \cdot \mathbf{Q}_{s}\right|$ \\
$\mathrm{B}(n=20)$ & Warm front & $\geq 0$ & $\leq-10$ (isotherms \\
& & & east-west) \\
$\mathrm{C}(n=17)$ & Cold front & $\geq 0$ & $\leq-10$ (isotherms \\
& & & north-south) \\
$\mathrm{D}(n=19)$ & Convective & $\geq 0$ & $\geq 0$ \\
\hline
\end{tabular}

in higher-resolution analyses and forecasts. To that end, modern operational forecasters are quite likely to use higher-resolution products than the $\mathrm{R} 2$ data used here. We tested our partitioning scheme using both the NARR (32-km grid spacing) and CFSR $\left(0.5^{\circ}\right.$ grid spacing) and found that unsmoothed full-resolution $\mathbf{Q}_{s}$ and $\mathbf{Q}_{n}$ divergence patterns are extremely noisy fields and difficult to interpret (not shown). Therefore, we recommend that the forecaster smooth and/or slightly degrade the resolution of the higher-resolution products to better ascertain physical insight from $\mathbf{Q}_{s}$ and $\mathbf{Q}_{n}$ divergence; when we did this with the NARR and CFSR, the magnitudes and structures of both fields were nearly identical to those from R2. By definition (e.g., Keyser et al. 1988; Milrad et al. 2010a,b), $\mathbf{Q}_{s}$ and $\mathbf{Q}_{n}$ divergence will show synoptic-scale and mesoscale forcing for ascent, respectively, by using synoptic-scale mass fields in the calculations.

We use the distinctions between Q-vector components to partition our heavy (top $10 \%, n=166$ ) precipitation events into four types, as detailed in Table 2. To partition our cases, the criteria in Table 2 needed to be met at $t=-6,0$, and/or $+6 \mathrm{~h}$, as there was some caseto-case temporal variability in the predominant ascent forcing (not shown).

Our partitioning scheme is similar to that of Maddox et al. (1979) in that it separates events that primarily involve synoptic-scale QG forcing for ascent (i.e., type A) from those that do not (i.e., types B, C, and D). However, we proceed further by subdividing our frontal cases into warm frontal (type B) and cold frontal (type C) events, and having a separate category (type D) that did not exhibit any $\mathbf{Q}$-vector convergence or particularly apparent dynamical forcing for ascent. The thresholds of $-10 \times 10^{-17}$ for $\mathbf{Q}_{n}$ divergence in types B and C are solely used to indicate that the values in every case were indeed convergent, and not near zero, unlike many cases in type D. Overall, 158 of the 166 heavy precipitation cases were classified into types A-D; only 8 cases did not fit into any category. 
To demonstrate our partitioning methodology, Fig. 3 shows examples of each type at $t=0 \mathrm{~h}$; other cases in each type were found to be similar. Case examples are used in Fig. 3 instead of composites to justify our manual partitioning, because it was performed on a case-by-case basis; the composite evolutions of the $\mathbf{Q}_{s}$ and $\mathbf{Q}_{n}$ divergence are subsequently discussed in section 4 .

For type A, Figs. 3a,b show an MSLP cyclone just southwest of the Montreal region. Ahead of the cyclone, there is both $\mathbf{Q}_{s}$ (Fig. 3a) and $\mathbf{Q}_{n}$ (Fig. 3b) convergence over Montreal. Type A cases generally feature MSLP cyclones that originate south or southwest of the Montreal region and proceed to track either through or near the SLRV from the Great Lakes, or up through New England near the Atlantic coast. The cyclones that tracked through New England [Dookhie (2011) referred to these as "back-bent warm front" cases] tended to be stronger (not shown), but the synoptic-scale similarities between the two cyclone tracks were such that we could consider them as one large group. Finally, we note that all eight ET cases included in this study were type A events (Table 3 ).

Type B cases are warm frontal events, and appear qualitatively similar to the "frontal events" described by Maddox et al. (1979), in which the heaviest precipitation falls on the cool side of the front. Figures $3 \mathrm{c}$, d show an MSLP cyclone similar in intensity to the cyclone evident in type A (Figs. 3a,b), but located farther to the west. Thus, synoptic-scale QG forcing for ascent $\left(\mathbf{Q}_{s}\right.$ convergence) never reaches the Montreal area (Fig. 3c). Instead, a broad area of $\mathbf{Q}_{n}$ convergence is located over CYUL (Fig. 3d), in association with a warm front ahead of the MSLP cyclone. The thickness contours (isotherms) are oriented west-east (Figs. 3c,d), in contrast to type C (cold frontal) events, in which they are oriented northsouth.

Type C cases are cold frontal events and appear qualitatively similar to the "synoptic" events detailed by Maddox et al. (1979). Isotherms in the Montreal region are oriented north-south, with a cold-stationary front located just west of Montreal, placing the heaviest precipitation on the warm side of the front (Maddox et al. 1979; LaPenta et al. 1995). The case shown in Figs. 3e,f is for the record-breaking precipitation event of November 1996 (Durnford 2001). The largest $\mathbf{Q}_{s}$ convergence is located far to the south of Montreal, ahead of a strong upper-tropospheric trough (Fig. 3e) and near a frontal wave MSLP cyclone located over the Appalachians (Durnford 2001). As one would expect with a northsouth-oriented cold-stationary front, a broad swath of $\mathbf{Q}_{n}$ (Fig. 3f) convergence is observed over Montreal (Fig. 3f).

We deem type $\mathrm{D}$ cases to be convective events. Figures $3 \mathrm{~g}$,h show that there is no $\mathbf{Q}_{s}$ or $\mathbf{Q}_{n}$ convergence in the vicinity of Montreal; in fact, some type D events were marked by $\mathbf{Q}_{s}$ and/or $\mathbf{Q}_{n}$ divergence (not shown), indicative of descent. This suggests that the forcing for ascent is either very minimal or on too small of a scale to be observed in the reanalysis. Figures $3 \mathrm{~g}$,h show a large MSLP anticyclone off the Eastern Seaboard (Bermuda high), with a weak MSLP cyclone evident in the western Great Lakes. We postulate that type D cases are generally associated with convection occurring in the presence of a warm, relatively unstable air mass, triggered by quick-moving short-wave upper-level vorticity maxima traveling through the large-scale ridge environment. This is further investigated and discussed in section 4 .

The histogram in Fig. 4 shows that the four event types have similar precipitation distributions, especially if one considers the record-breaking November 1996 event [largest event in type C; Durnford (2001)] to be an outlier, because it biases the type $\mathrm{C}$ mean precipitation amount (the median precipitation amount is similar for all four event types). Figure 4 suggests that no particular type systematically produces higher amounts of precipitation. In other words, each type features different mechanisms of and balances among lift, moisture availability, atmospheric stability, and, to some extent, precipitation duration, all of which we discuss in detail in section 4 . Finally, we should note that using a lower-resolution reanalysis may preferentially detect more cases with dominant $\mathbf{Q}_{s}$ convergence, when in fact both $\mathbf{Q}_{s}$ and $\mathbf{Q}_{n}$ convergence are occurring. Put another way, Fig. 4 shows that the majority of our events are cyclone (type A) events (dominated by $\mathbf{Q}_{s}$ convergence), whereas a higherresolution reanalysis (e.g., CFSR) may be capable of detecting higher values of $\mathbf{Q}_{n}$ convergence in a particular event, which would subsequently be categorized as type $\mathrm{B}$ or $\mathrm{C}$. This would not change the composite synopticscale characteristics of our events, but it could ostensibly alter the typing histogram of heavy events (Fig. 4).

\section{Synoptic-dynamic analysis of heavy events}

Doswell et al. (1996) used an ingredients-based methodology as a basis for examining flash-flooding events, wherein the ingredients are ascent, moisture, and instability. Gyakum (2008) proposed that the amount of precipitation was related to the amount of moisture and instability, for a given forcing for ascent; in other words, ascent will be more conducive to precipitation in warmer, more humid air masses. We consider the Doswell et al. (1996) and Gyakum (2008) methodologies in choosing and describing our composite fields.

To create a similar number of cases in each composite, we use the 25 median (by precipitation amount) type $\mathrm{A}$ ( $n=$ 103) cases, since types B-D each contain approximately 

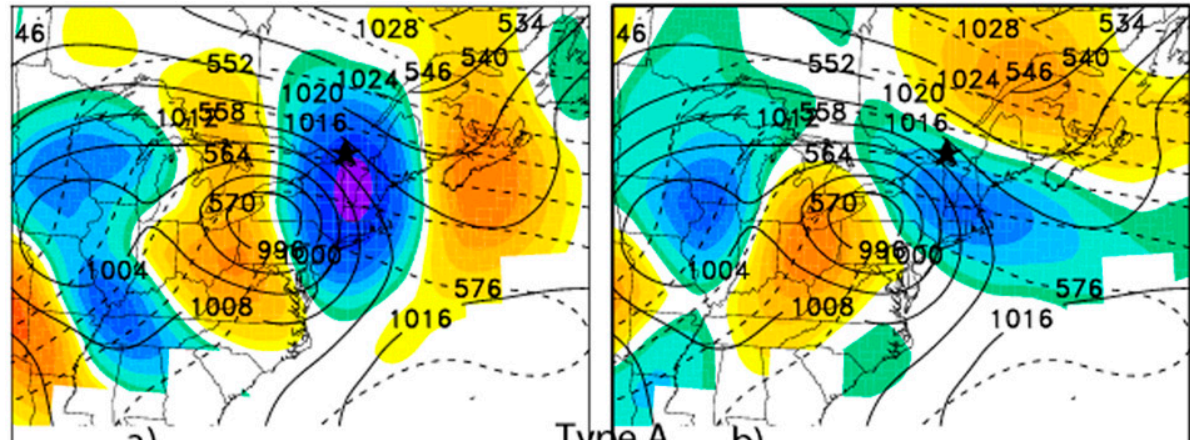

a)

Type $A$ b)

$\begin{array}{llllllllll}-200 & -120 & -60 & -20 & 0 & 20 & 60 & 120 & 200\end{array}$
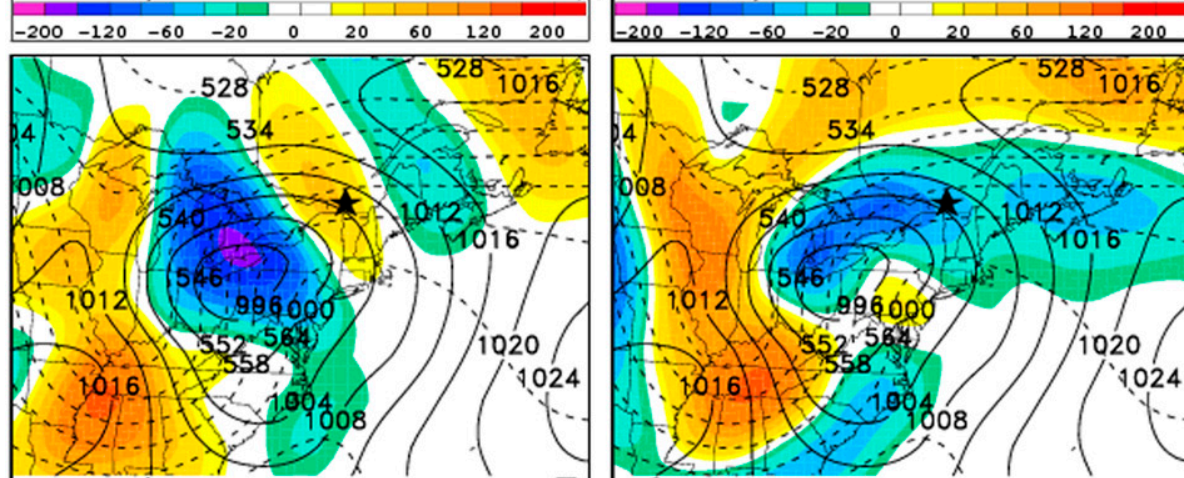

c)
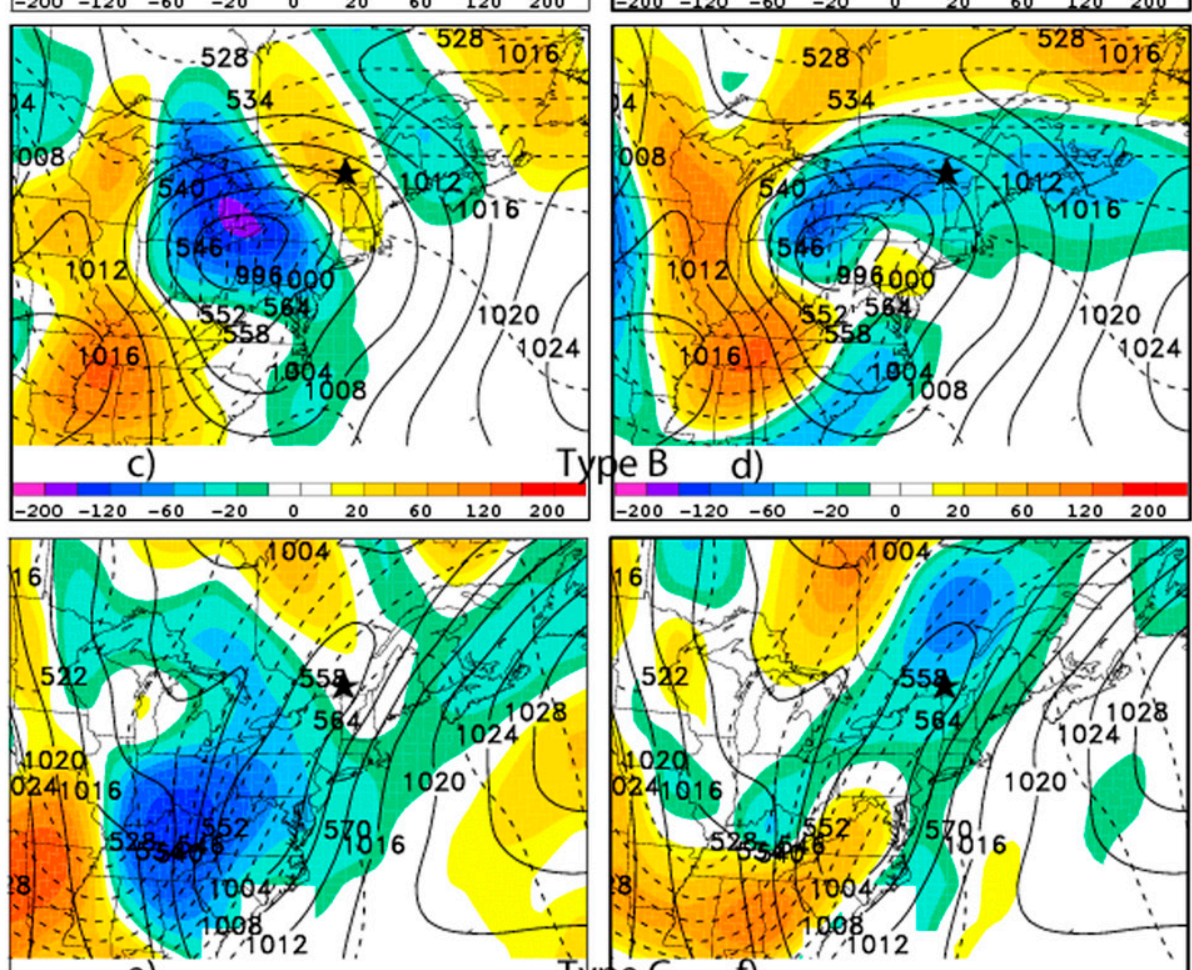

e)

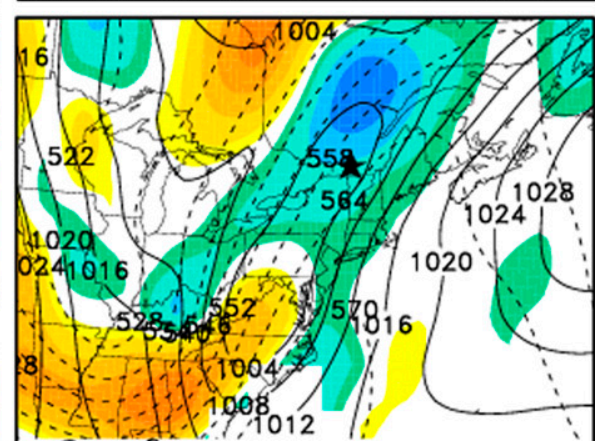

Type C

\section{f)}

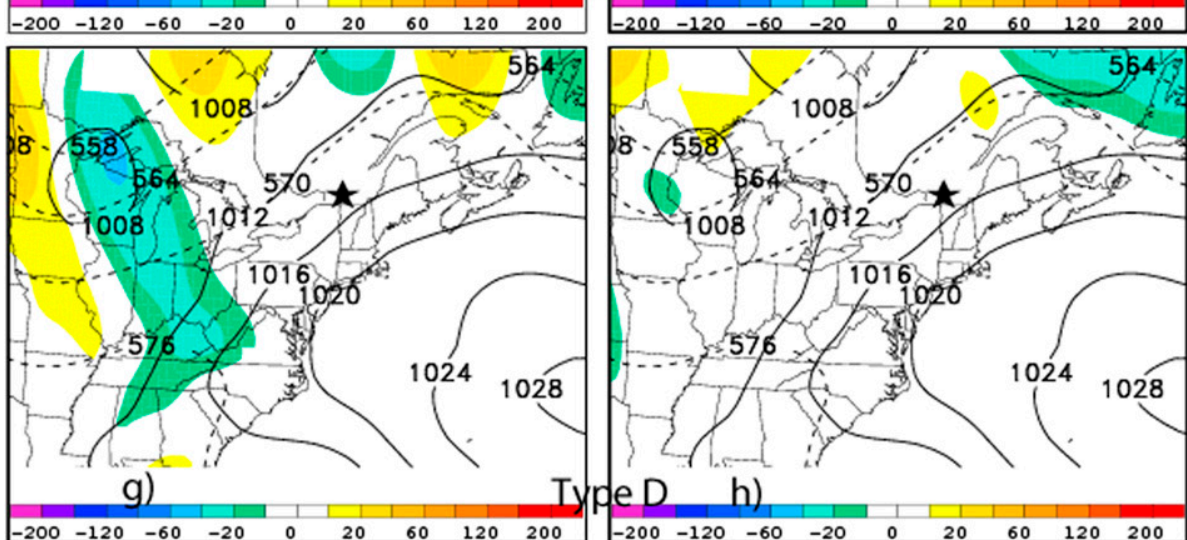

FIG. 3. A sample event at $t=0 \mathrm{~h}$ of (left) the 1000-500-hPa layer-averaged $\mathbf{Q}_{s}$ and (right) $\mathbf{Q}_{n}$ divergence $\left(\times 10^{-17} \mathrm{~K} \mathrm{~m}^{-2} \mathrm{~s}^{-1}\right.$, shaded cool colors for convergence); and (left), (right) MSLP (hPa, solid contours) and 1000-500-hPa thickness (dam, dashed contours) for: (a),(b) type A (0600 UTC 6 Oct 1995), (c),(d) type B (1200 UTC 1 Nov 1994), (e),(f) type C (1800 UTC 8 Nov 1996), and (g),(h) type D (0000 UTC 31 Jul 2004). For reference, CYUL is marked with a black star. 
TABLE 3. Based on the climatology of Milrad et al. (2013), the number of cases of ET that resulted in a heavy precipitation event at CYUL as classified by type.

\begin{tabular}{cc}
\hline \hline Type & No. of ET cases \\
\hline A $(n=103)$ & 8 \\
B $(n=20)$ & 0 \\
C $(n=17)$ & 0 \\
D $(n=19)$ & 0 \\
\hline
\end{tabular}

20 cases. We tried other combinations of type A cases (e.g., selecting 25 cases at random) and our composite results did not substantively change. Finally, we tested the stability of our composites by examining spaghetti plots and calculating the root-mean-square error (RMSE) for each composite type (not shown). While the amplitude of each composite feature (e.g., 500-mb trough) is somewhat variable within each type, the overall composite results are consistent with the overwhelming majority of individual cases within each group.

\section{a. 500-hPa height- $\mathbf{Q}_{s}$ divergence composites}

Figure 5 shows that in type A events, a precursor negative height anomaly is evident over the northern plains at $t=-48 \mathrm{~h}$ (Fig. 5a) and becomes statistically significant by $t=-24 \mathrm{~h}$ (Fig. 5c). Ahead of the composite mean $500-\mathrm{hPa}$ trough $\mathbf{Q}_{s}$ convergence is evident, indicative of synoptic-scale QG forcing for ascent [Eqs. (1)-(4)]. The negative 500-hPa height anomaly subsequently moves toward the Montreal region. By $t=$ $-12 \mathrm{~h}$, a statistically significant (at the $99 \%$ confidence interval) $-60-\mathrm{m}$ anomaly is present over the western Great Lakes (Fig. 5d), while strong $\mathbf{Q}_{s}$ convergence is located just west of Montreal. At the same time, a downstream positive $500-\mathrm{hPa}$ height anomaly and composite mean ridge are located over northern New England (Fig. 5d). At $t=0 \mathrm{~h}$ (Fig. 5e), type A events are characterized by a neutral to slightly negatively tilted $500-\mathrm{hPa}$ trough and strong $\mathbf{Q}_{s}$ convergence over Montreal. In addition, the magnitude of the $\mathbf{Q}_{s}$ convergence at $t=0 \mathrm{~h}$ (Fig. 5e) is the largest of any of the four types.

In the type $\mathrm{B}$ composite, the primary precursor synopticscale feature is a statistically significant positive $500-\mathrm{hPa}$ height anomaly centered just south of Montreal at $t=$ $-48 \mathrm{~h}$ (Fig. 6a). This feature moves more slowly than the precursor mean height features in type A. A composite mean trough is evident over the western Great Lakes region at $t=-12 \mathrm{~h}$ (Fig. 6d), although the associated negative anomaly is not statistically significant at any time. The negative height anomaly propagates toward Montreal, such that there is an anomaly couplet evident by $t=0 \mathrm{~h}$ (Fig. 6e). However, the composite mean 500-hPa trough and associated $\mathbf{Q}_{s}$ convergence remain well to the west of Montreal at $t=0 \mathrm{~h}$. In addition, both the upstream 500-hPa composite mean trough and $\mathbf{Q}_{s}$ convergence are considerably weaker than in type A events (Fig. 5e), consistent with type B cases being predominantly frontal events. Finally, note the decreasing wavelength apparent in the downstream ridge from $t=$ -24 to $+12 \mathrm{~h}$ (Figs. 6c,f); upon examining spaghetti plots (one height contour for each case; not shown), we find that this is not an artifact of the compositing

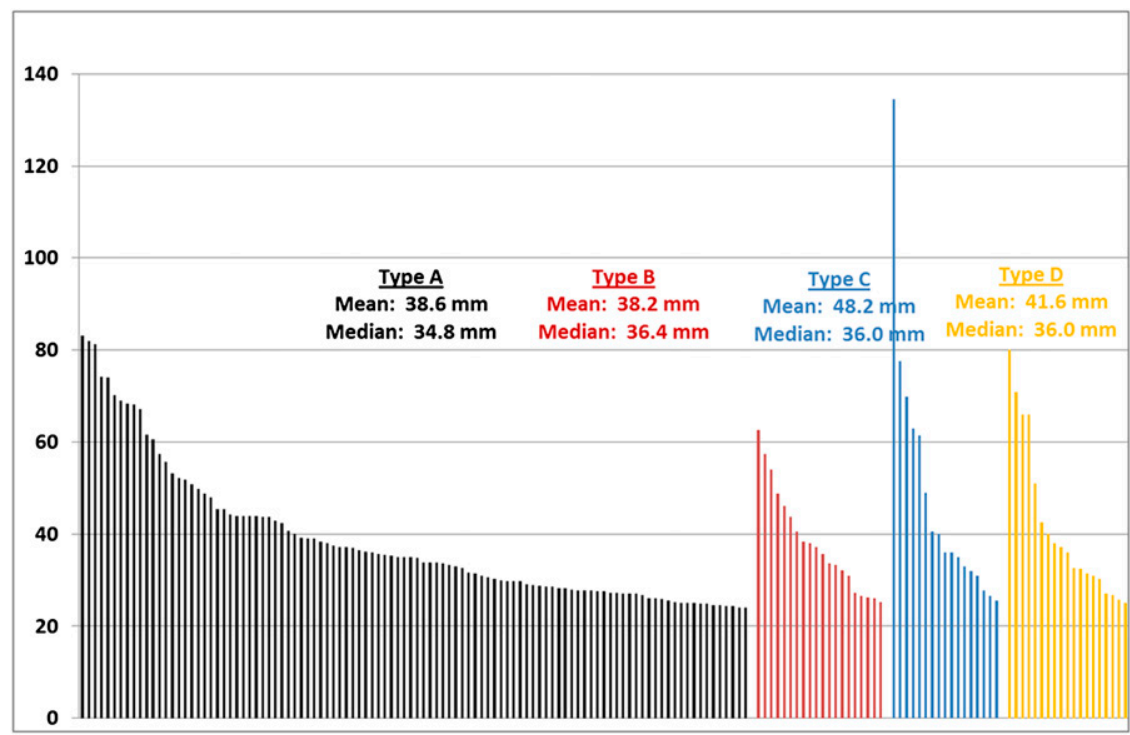

FIG. 4. Histogram of precipitation event amount $(\mathrm{mm})$ by heavy precipitation event type. Type A $(n=103$, black $), \mathrm{B}(n=20$, red $), \mathrm{C}(n=17$, blue $)$, and $\mathrm{D}(n=19$, yellow $)$. The mean and median values are also listed. 


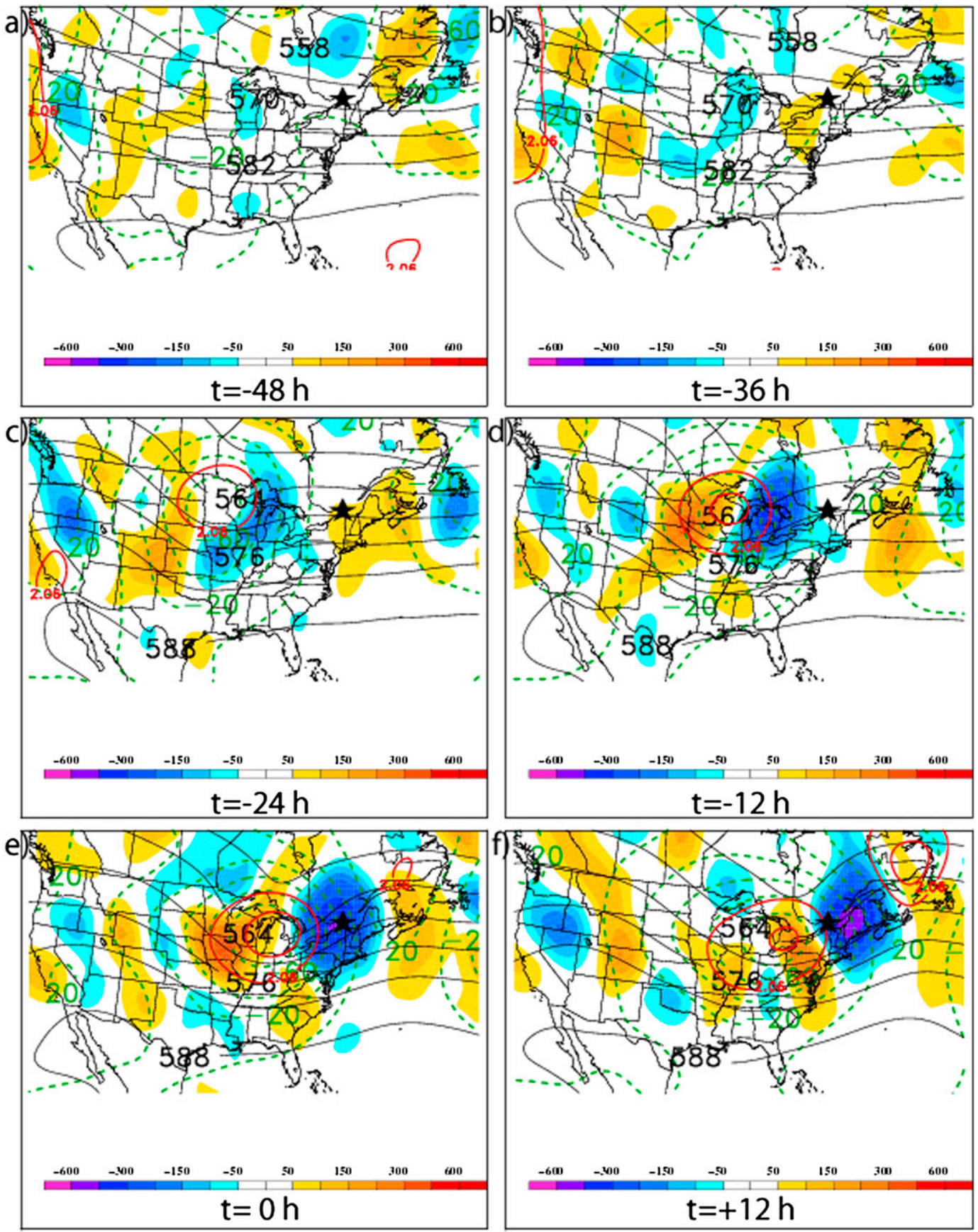

FIG. 5. For the 25 median type A $(n=103)$ events, composite $1000-500-h P a$ layer-averaged $\mathbf{Q}_{s}$ divergence ( $\times 10^{-17} \mathrm{~K} \mathrm{~m}^{-2} \mathrm{~s}^{-1}$, shaded cool colors for convergence), 500-hPa geopotential height anomalies with respect to a 30-yr (1979-2008) weighted monthly climatology (dam, green dashed contours), composite 500-hPa geopotential height (dam, solid black contours), and statistical significance of the 500-hPa geopotential height anomalies at the $95 \%$ and $99 \%$ confidence levels according to the Student's $t$ test (outer and inner solid red contours, respectively), at $t=(\mathrm{a})-48$, (b) -36 , (c) -24 , (d) -12 , (e) 0 , and (f) $+12 \mathrm{~h}$.

procedure and is suggestive of downstream ridge enhancement due to WAA and/or diabatic heating from heavy precipitation. While the quantification of amplitude uncertainty versus phase uncertainty throughout our composites would be an interesting exercise, it is beyond the scope of this paper and we thus leave it for future work.

The type C composite exhibits the most amplified 500 -hPa height pattern of any type. At $t=-48 \mathrm{~h}$, a large 

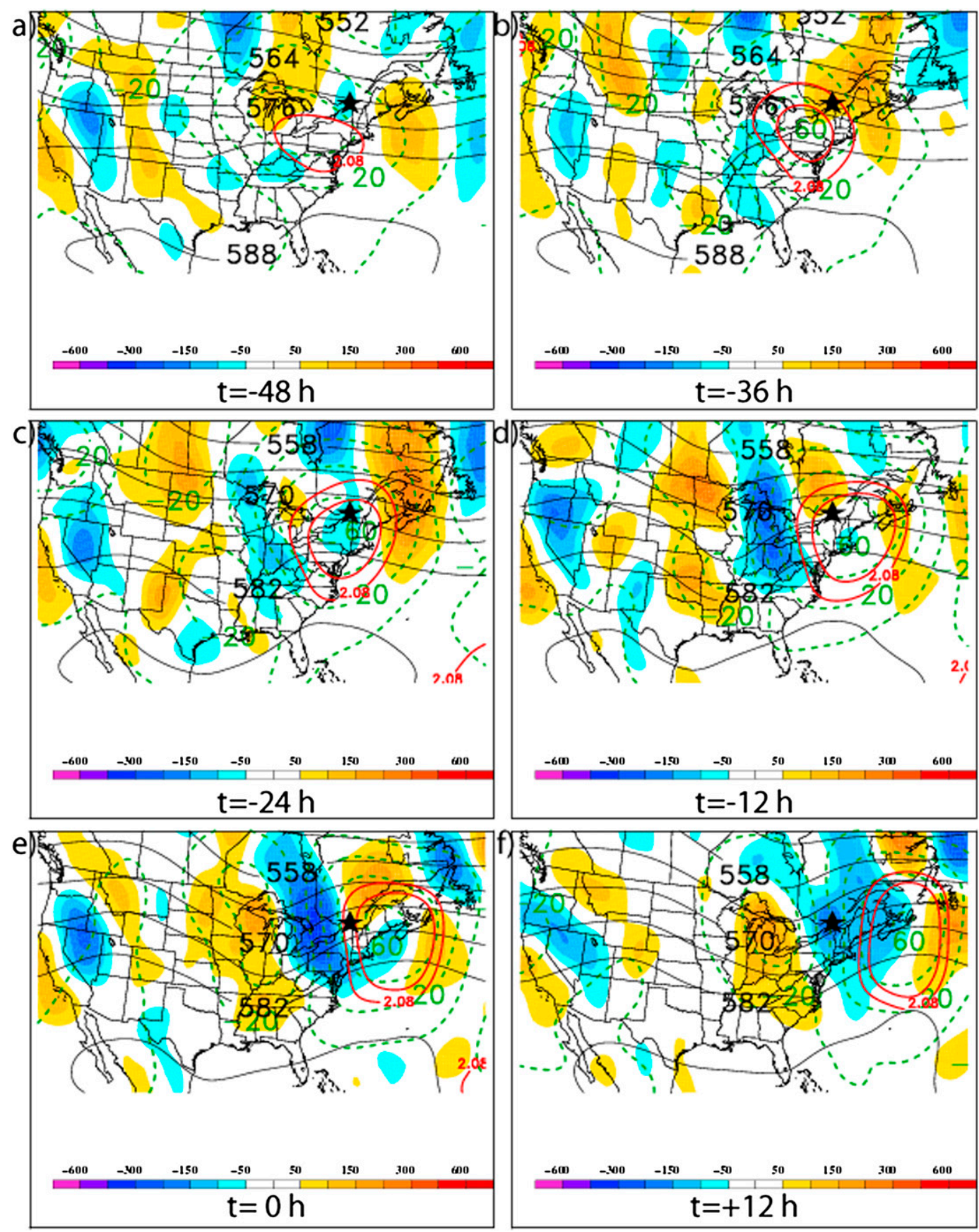

FIG. 6. As in Fig. 5, but for all type B $(n=20)$ events.

statistically significant negative 500-hPa height anomaly and composite mean trough are centered over southern Saskatchewan, while a large statistically significant positive height anomaly and composite mean ridge are located near the Appalachians (Fig. 7a). Both anomalies are statistically significant as early as $t=-72 \mathrm{~h}$ (not shown), $24 \mathrm{~h}$ earlier than any anomaly in any other type. By $t=-12 \mathrm{~h}$ (Fig. 7d) and $t=0 \mathrm{~h}$ (Fig. 7e), the anomaly couplet is the strongest of any type at any time. The large amplitudes and long duration of the anomalies are suggestive of long-duration northward transport of moisture and high- $\theta_{e}$ air, discussed in section $4 \mathrm{c}$. However, the $\mathbf{Q}_{s}$ convergence over the Montreal region remains relatively weak throughout the composite evolution (Figs. 7a-f), especially compared to type A events (Fig. 5). From the 500-hPa composite mean field, we can see that the strongest 

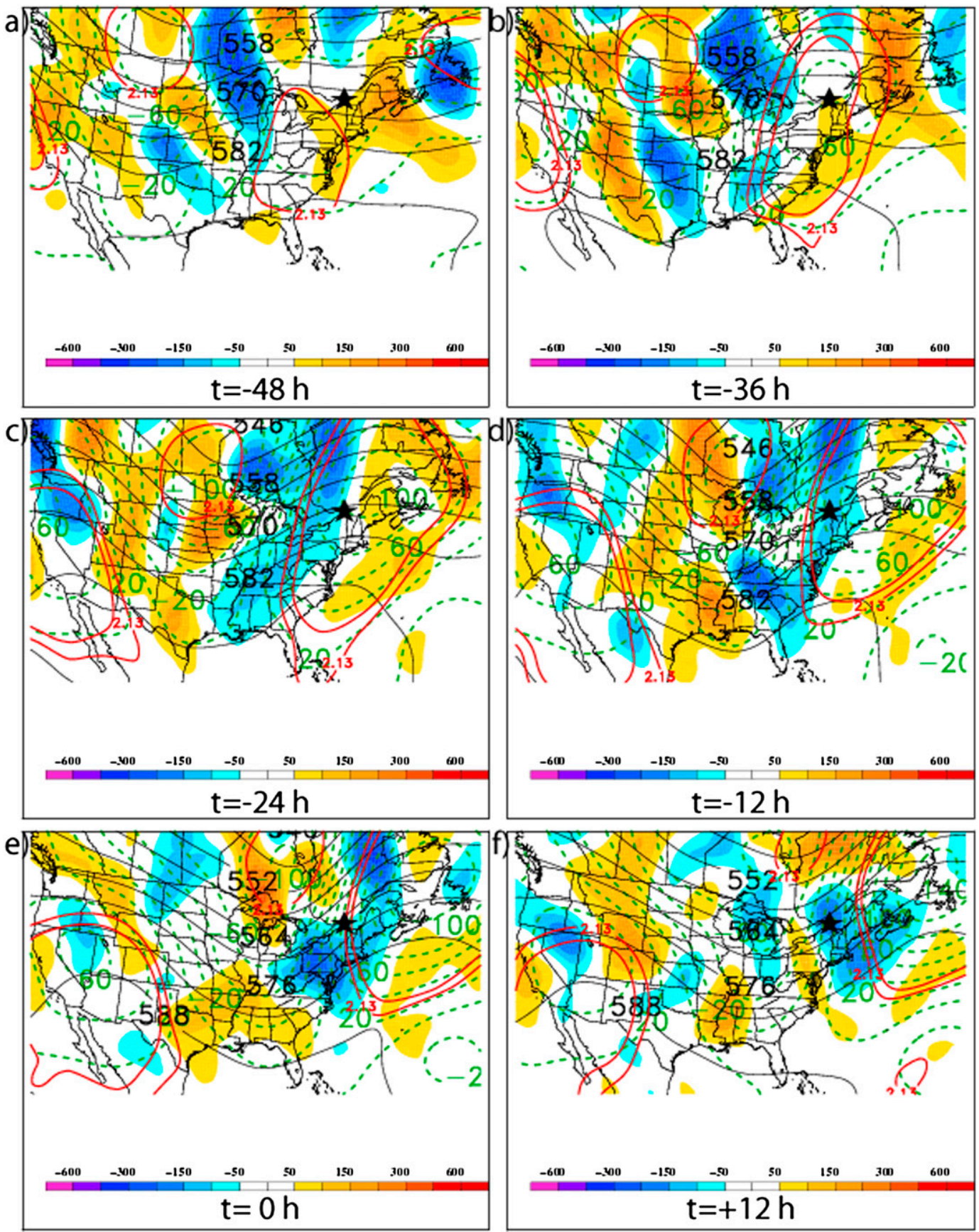

FIG. 7. As in Fig. 5, but for all type C $(n=17)$ events.

$\mathbf{Q}_{s}$ convergence at $t=0 \mathrm{~h}$ is located in two places: 1$)$ over the mid-Atlantic (Fig. 7e) well south of Montreal and 2) in northeastern Quebéc near the Labrador border (Fig. 7e), well to the north of Montreal. The height anomalies from $t=-12$ to $+12 \mathrm{~h}$ (Figs. $7 \mathrm{~d}-\mathrm{f}$ ) are also located well to the north of the corresponding features in types A and B (Figs. 5 and 6). Combined with relatively weak $\mathbf{Q}_{s}$ convergence, these observations support the assertion of type $\mathrm{C}$ as featuring cold or stationary frontal events.

The type D composite differs from all other types in that (a) no negative 500 -hPa height anomaly is evident in the vicinity of Montreal throughout the composite evolution (Fig. 8), and (b) $\mathbf{Q}_{s}$ convergence is not observed over Montreal at any time. Instead, a large statistically significant positive 500-hPa height anomaly 


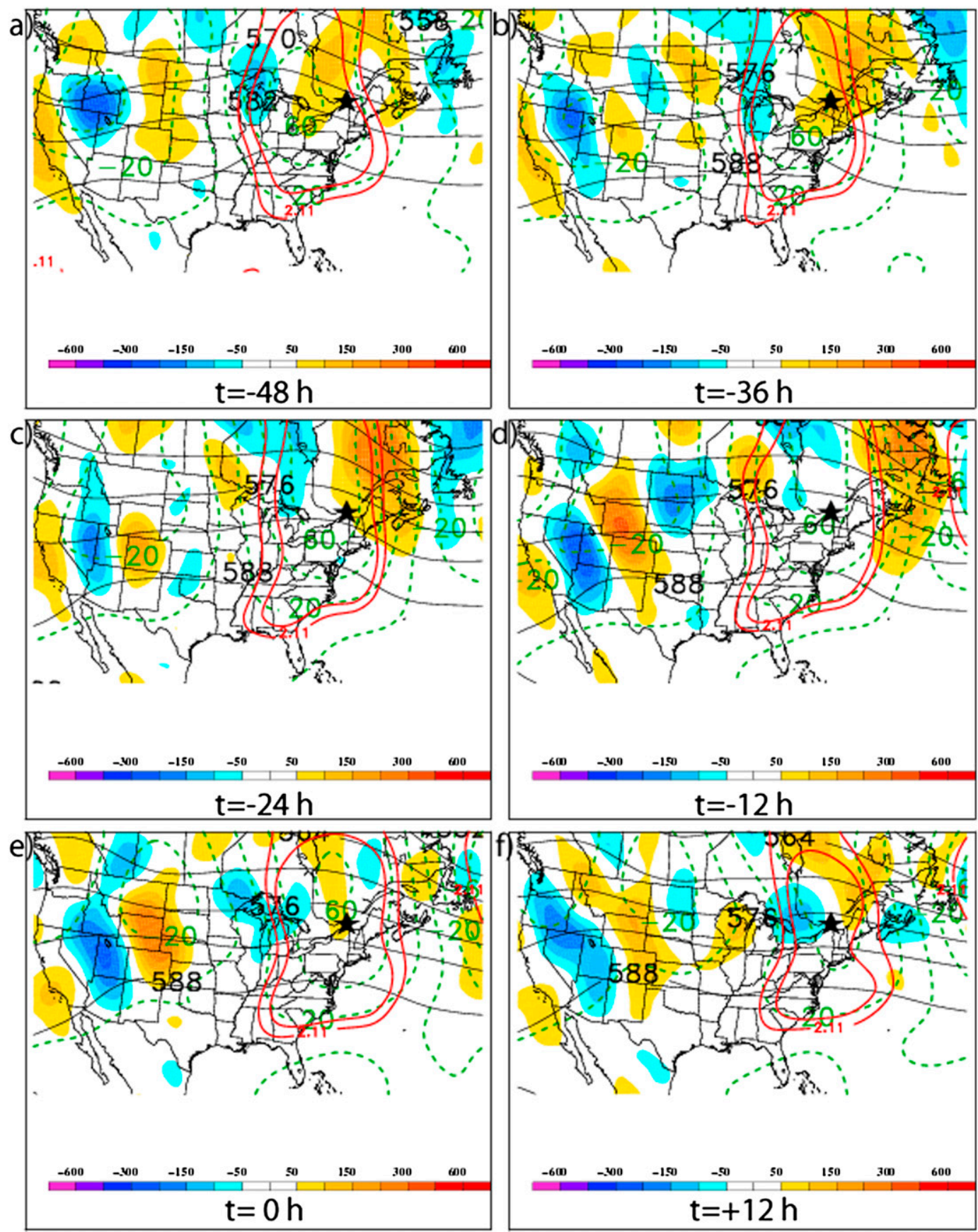

FIG. 8. As in Fig. 5, but for all type D $(n=19)$ events.

and associated composite mean 500-hPa ridge are centered near Montreal throughout the composite evolution (Fig. 8). This suggests little to no synoptic-scale forcing for ascent and the presence of a warm, humid air mass over Montreal. However, examination of individual cases (not shown) shows that weak short-wave midtropospheric troughs are evident upstream of Montreal (within the longwave ridge environment) in some cases, and may serve as a weak synoptic-scale "trigger" for the type D convective events; this is discussed further in sections $4 \mathrm{~b}-\mathrm{d}$.

\section{b. MSLP- $\mathbf{Q}_{n}$ divergence composites}

Figure 9 shows that for type A events, a statistically significant negative MSLP anomaly is first evident over Illinois at $t=-36 \mathrm{~h}$ (Fig. 9b), downstream of the 

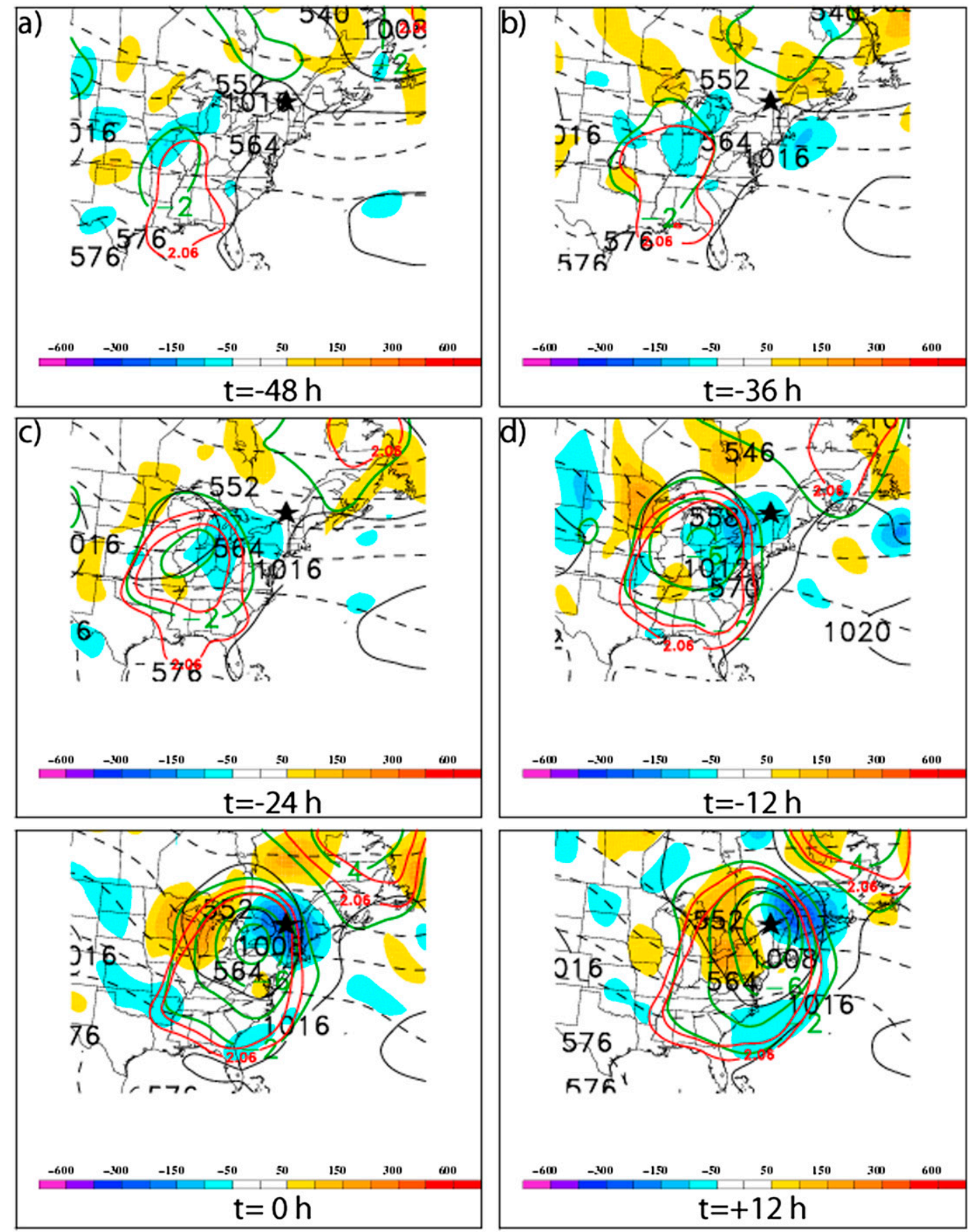

FIG. 9. As in Fig. 5, but for $\mathbf{Q}_{n}$ divergence and MSLP anomalies (hPa, solid green contours), composite MSLP (hPa, solid contours), composite 1000-500-hPa thickness (dam, black dashed contours), and statistical significance of the MSLP anomalies.

corresponding 500-hPa composite mean trough (Fig. 5a). By $t=-12 \mathrm{~h}$, a 1012-hPa composite cyclone and $-6-\mathrm{hPa}$ anomaly are evident over the Great Lakes (Fig. 9d), and at $t=0 \mathrm{~h}$, a $1008-\mathrm{hPa}$ composite cyclone and $-8 \mathrm{-hPa}$ anomaly are located just upstream of Montreal, supporting the observation of strong synoptic-scale forcing for ascent ( $\mathbf{Q}_{s}$ convergence). Nonzero values of $\mathbf{Q}_{n}$ convergence are also observed over Montreal from $t=$ -12 to +12 h (Figs. 9d-f). This suggests that mesoscale QG forcing for ascent (e.g., frontogenesis with the warm front ahead of the MSLP cyclone) plays a small role in type A events, albeit a smaller one than synoptic-scale 

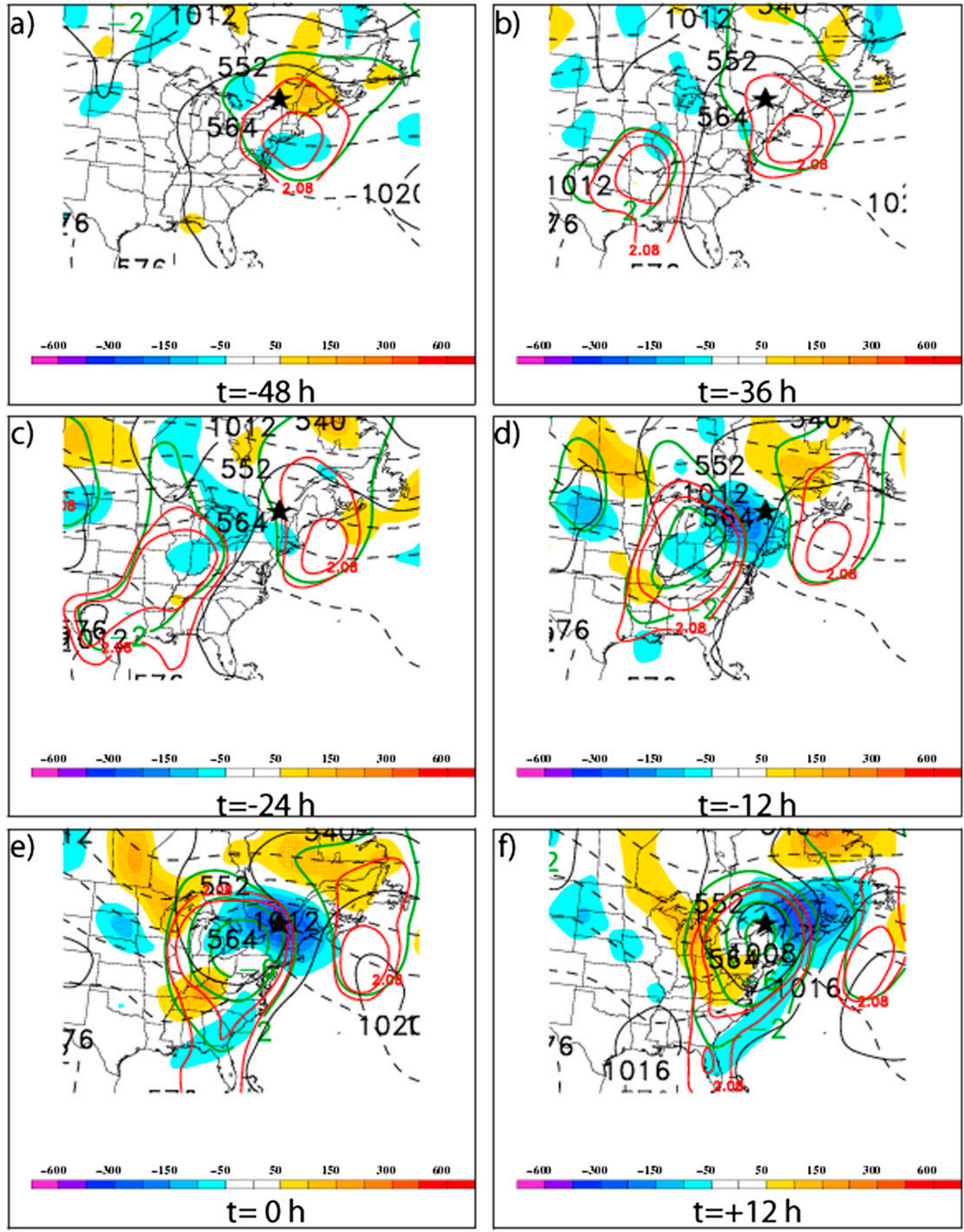

FIG. 10. As in Fig. 9, but for all type B.

QG forcing for ascent (Fig. 5). Finally, a statistically significant positive MSLP anomaly and composite MSLP anticyclone are evident downstream of CYUL, starting at $t=-24 \mathrm{~h}$ (Figs. 9c-f), and corresponding to the 500-hPa ridge (Figs. 5c-f). The downstream MSLP anticyclone coupled with the upstream MSLP cyclone features suggest southerly and southeasterly geostrophic flow into the Montreal region (Figs. 9c-e).
For type B events, Fig. 10 shows that the primary precursor feature is a statistically significant positive MSLP anomaly (composite MSLP anticyclone) located near Montreal at $t=-48 \mathrm{~h}$ (Fig. 10a). This feature is relatively persistent throughout the composite evolution (Figs. 10a-f). Meanwhile, a weak negative MSLP anomaly is evident in the lower Mississippi Valley at $t=$ $-36 \mathrm{~h}$ (Fig. 10b), in association with a weak southern 

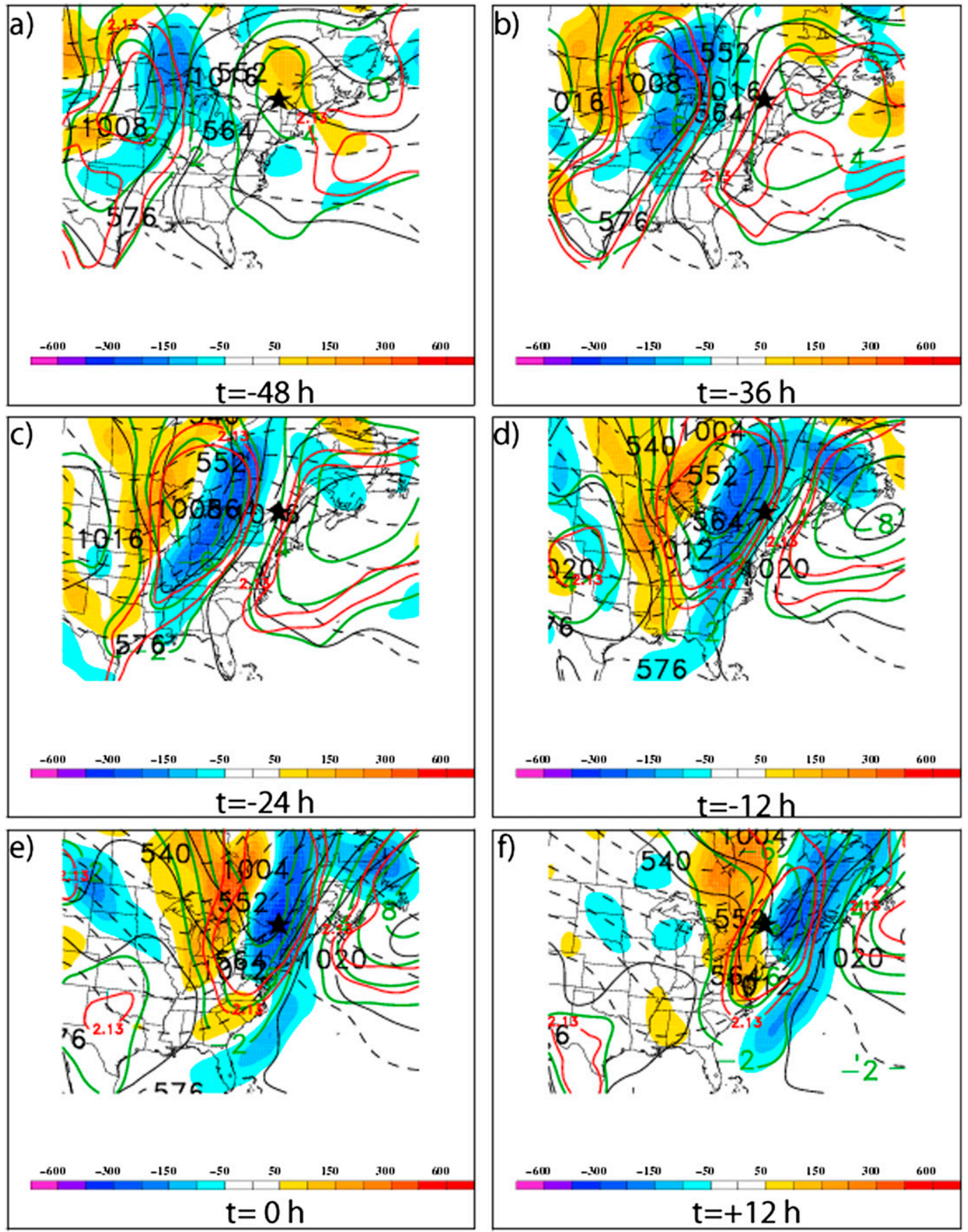

FIG. 11. As in Fig. 9, but for all type C.

stream midtropospheric disturbance (Fig. 6b). The orientation of the two anomalies is important here, as they help to establish anomalous southerly geostrophic flow on the western side of the MSLP anticyclone, which advects warm, moist air northward (see section $4 \mathrm{c}$ ). The importance of the warm front in type B cases is exemplified by strong $\mathbf{Q}_{n}$ convergence over Montreal from $t=-12$ to $+12 \mathrm{~h}$ (Figs. 10d-f). This $\mathbf{Q}_{n}$ convergence over Montreal is stronger than the $\mathbf{Q}_{s}$ convergence at the same times (Figs. 6d-f).

The type C composite shows a composite MSLP cyclone and statistically significant -6 -hPa anomaly evident in the northern plains at $t=-48 \mathrm{~h}$ (Fig. 11a). Meanwhile, a strong composite MSLP anticyclone and statistically 
significant positive +4 -hPa MSLP anomaly are centered along the east coast of the United States (Fig. 11a). Both features proceed to move eastward, with the composite MSLP cyclone tracking to the north of Montreal (Figs. 11b-f). From $t=-48$ h (Fig. 11a) onward, the amplified MSLP features result in strong geostrophic southerly flow. By $t=-12 \mathrm{~h}$ (Fig. 11d) and $t=0 \mathrm{~h}$ (Fig. 11e), the cold front (as evidenced by the north-south-oriented 1000-500-hPa thickness contours) dragging southward from the center of the MSLP cyclone is located just west of Montreal. Accordingly, very large values of $\mathbf{Q}_{n}$ convergence are observed over Montreal at $t=-12$ and $0 \mathrm{~h}$ (Figs. 11d-e). This suggests strong frontogenesis and mesoscale QG forcing for ascent in association with the cold frontal passage, as the magnitude of $\mathbf{Q}_{n}$ convergence greatly exceeds the magnitude of $\mathbf{Q}_{s}$ convergence. Furthermore, the high-amplitude ridge puts Montreal fully in the warm sector prior to the cold frontal passage (Figs. 7 and 11), which precludes any warm-frontal frontogenesis, and contributes to the north-south orientation of the $\mathbf{Q}_{n}$ convergence. Finally, while examining each type $\mathrm{C}$ case, we found some variability in event (and large $\mathbf{Q}_{n}$ convergence) duration; that is, some of the cold fronts moved very slowly through the Montreal region, essentially becoming a stationary front with weak frontal wave development to the south of Montreal. The November 1996 case (Durnford 2001; Figs. $3 \mathrm{e}, \mathrm{f}$ ) is an example of such a case, and these cases tended to result in some of the largest precipitation totals in the entire 1979-2008 time period.

In type D, a composite mean MSLP anticyclone (Bermuda high) is located off the east coast (Fig. 12). Weak southerly geostrophic flow is occurring on the western side of the anticyclone, into the Montreal region (Figs. 12a-f). Meanwhile, a statistically significant but weak MSLP negative anomaly is first evident over the central plains at $t=-48 \mathrm{~h}$ (Fig. 12a) and slowly moves eastward. However, at $t=0 \mathrm{~h}$ (Fig. 12e), the weak negative MSLP anomaly and composite cyclone remain over the western Great Lakes, far removed from Montreal. Figure 12 also demonstrates that little to no $\mathbf{Q}_{n}$ convergence is evident throughout the type $\mathrm{D}$ composite evolution. Combined with the observation of no $\mathbf{Q}_{s}$ convergence in Fig. 8, type D events appear to be associated with triggers (lift) too small in magnitude or scale to show up in the composites; this is further discussed in sections $4 \mathrm{c}$ and $4 \mathrm{e}$.

\section{c. $\theta_{e}$ composites}

We utilize composites and composite anomalies of $850-\mathrm{hPa}$ equivalent potential temperature $\left(\theta_{e}\right)$ in this section to discuss the density characteristics of the air mass in each composite type. In the type A composite, a positive $\theta_{e}$ anomaly is first evident over Florida at $t=$ -48 h (Fig. 13a). Anomalously high $\theta_{e}$ air is advected northward, and by $t=0 \mathrm{~h}, \mathrm{a}+9-\mathrm{K}$ anomaly and associated composite mean $\theta_{e}$ "ridge" are located over Montreal.

In the type B composite, a statistically significant positive $\theta_{e}$ anomaly is evident over the Appalachians at $t=-48 \mathrm{~h}$ (Fig. 14a). The positive anomaly is collocated with the anomalous southerly geostrophic flow on the western side of the composite MSLP anticyclone (Fig. 10a). High- $\theta_{e}$ air is advected northward as the warm front slowly advances toward Montreal (Figs. 14a-f). By $t=0 \mathrm{~h}, \mathrm{a}+12-\mathrm{K}$ anomaly is evident over Montreal. At $t=-12$ and $0 \mathrm{~h}$ (Figs. 14d,e), the composite mean values of $\theta_{e}$ are $5-10 \mathrm{~K}$ higher in type B than in type A. This suggests that while the overall QG forcing for ascent (almost entirely $\mathbf{Q}_{n}$ convergence) might be weaker in type B cases than in type A cases, the air mass is warmer and more humid around the times of heaviest precipitation (Figs. 14d-f).

The type $\mathrm{C}$ composite shows a large plume of statistically significant anomalously high- $\theta_{e}$ air at $t=-48 \mathrm{~h}$ (Fig. 15a), which appears to originate in the southern plains and western Gulf of Mexico. The high- $\theta_{e}$ air is advected farther northeastward throughout the composite evolution, in association with the amplified composite MSLP structures observed in Fig. 11, such that by $t=-12 \mathrm{~h}, \mathrm{a}+16-\mathrm{K}$ anomaly is over Montreal (Fig. 15e), the largest $\theta_{e}$ anomaly in any type. The anomalously high $\theta_{e}$ air at Montreal persists through $t=0 \mathrm{~h}$ (Fig. 15e), prior to the passage of the cold front. Composite mean $\theta_{e}$ values are $>325 \mathrm{~K}$ at both $t=-12$ and $0 \mathrm{~h}$ (Figs. 15d,e), and $\geq 5 \mathrm{~K}$ warmer than in types A and B. In summary, the thermodynamic setup (extensive long-lived advection of high- $\theta_{e}$ air) in type $C$ events results in a very warm and unstable air mass at Montreal, which combined with strong frontal forcing for ascent $\left(\mathbf{Q}_{n}\right.$ convergence) is conducive to occasionally producing the largest precipitation amounts in the study period, such as the record 1996 event (Durnford 2001).

The $\theta_{e}$ composite for type $\mathrm{D}$ shows an evolution that is distinct from the other types. At $t=-48 \mathrm{~h}$ (Fig. 16a), anomalously high $-\theta_{e}$ air is already present in the Montreal region. The center of the dome of anomalously high $-\theta_{e}$ air slowly migrates from the Great Lakes toward Montreal throughout the composite evolution (Fig. 16). Composite mean $\theta_{e}$ values are nearly $330 \mathrm{~K}$ at both $t=$ -12 and $0 \mathrm{~h}$ (Fig. 16d,e), 3-5 K warmer than in type C (and much warmer than in types A and B). This suggests that a very warm and humid air mass exists throughout most of the northern United States and southern Canada, for at least 2 days before the time of maximum precipitation. The overall thermodynamic setup is quite different from types $\mathrm{A}-\mathrm{C}$, in which the warm moist air 

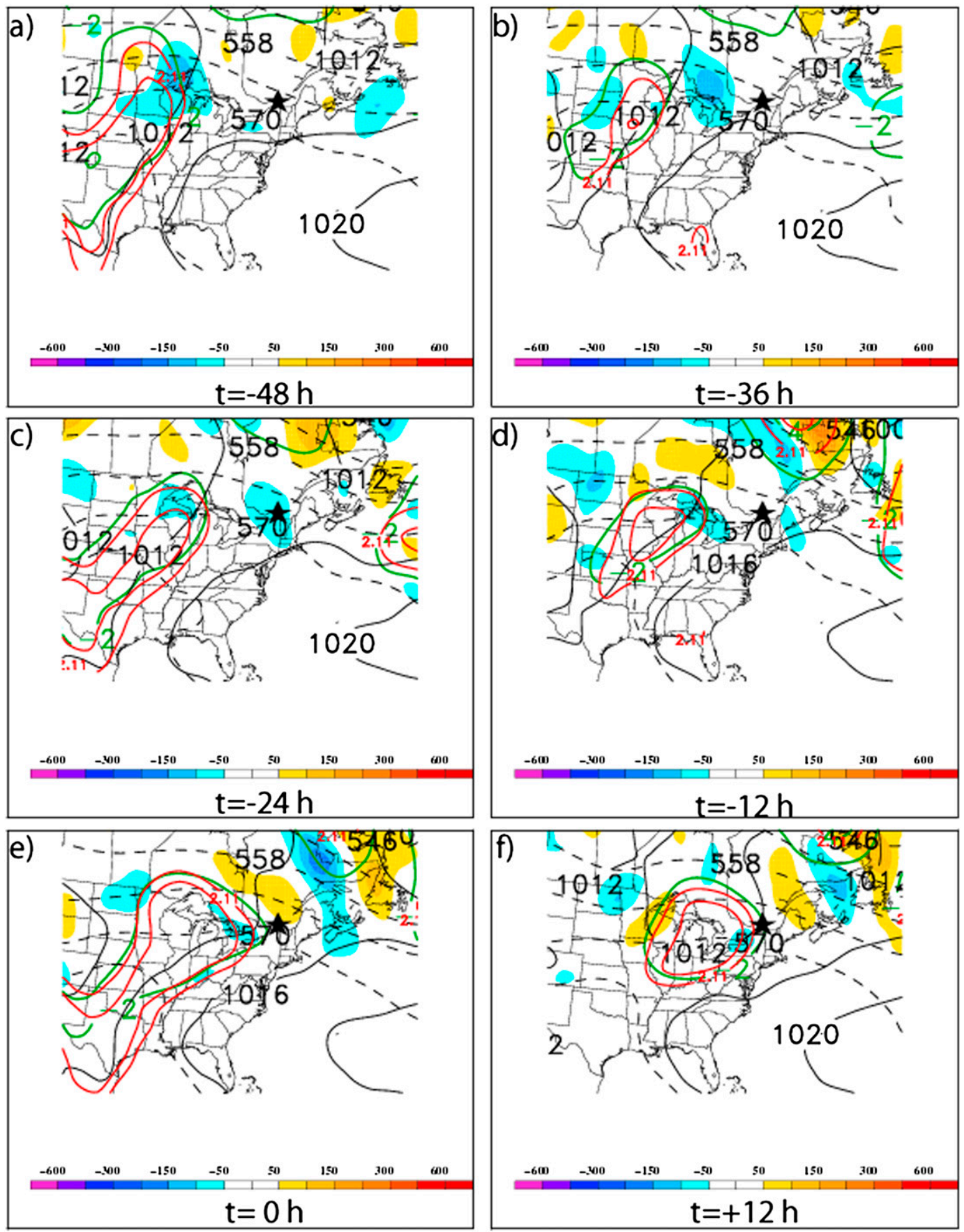

FIG. 12. As in Fig. 9, but for all type D.

mass is more transient (to varying degrees). Although the synoptic-scale forcing for ascent in type D cases is clearly minimal (Figs. 8 and 12), the characteristics of the air mass suggest that even the smallest of triggers might result in a heavy precipitation event. To that end, the 700-hPa height ridge flattens over time (Fig. 16), an indication that a weak short-wave trough may be passing through the long-wave ridge environment, which is supported by our $500-\mathrm{hPa}$ spaghetti plots of each type (not shown).

\section{d. Trajectory analysis}

The 5-day backward trajectories starting at $t=0 \mathrm{~h}$ are displayed in Fig. 17, for each case-corresponding 

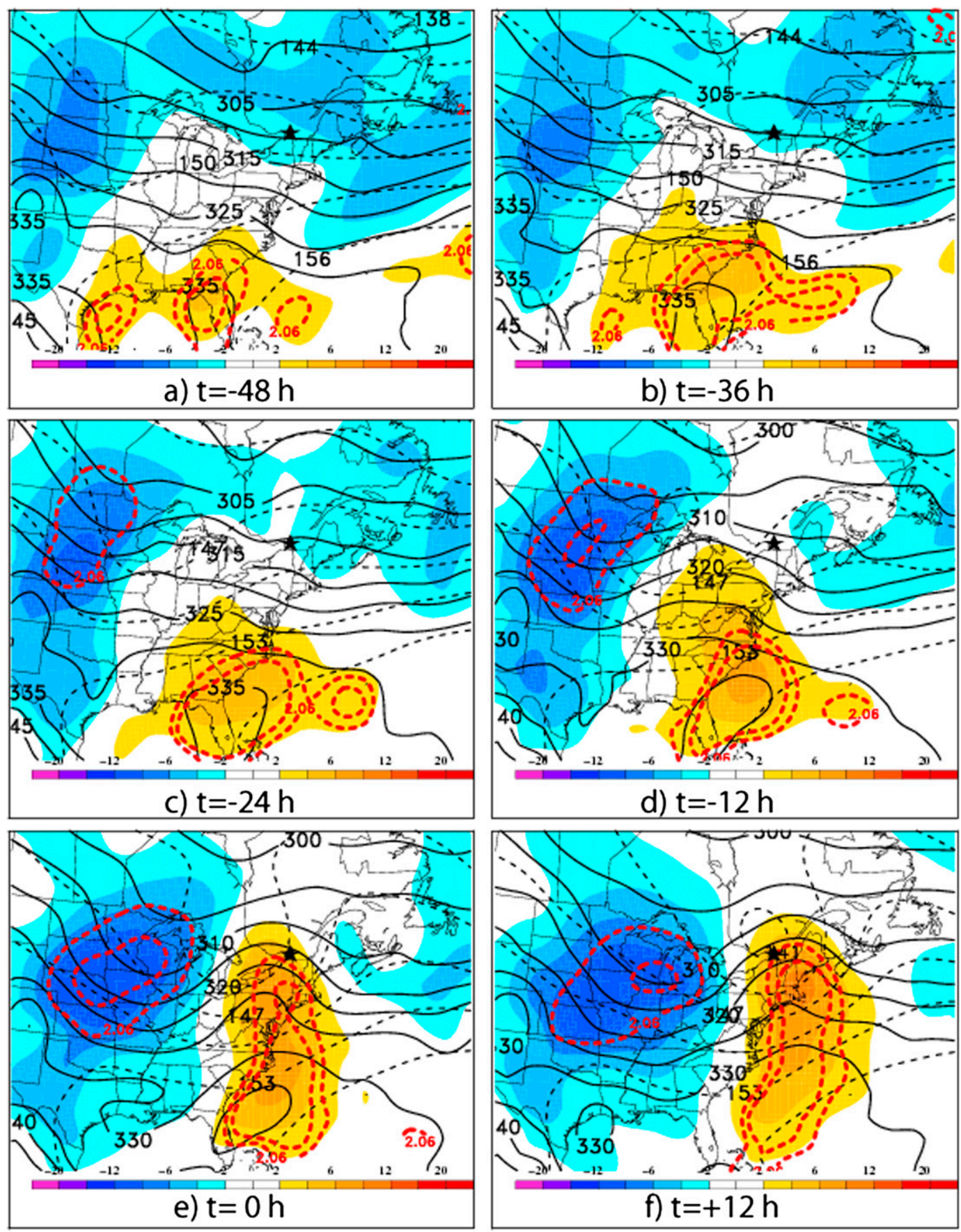

FIG. 13. As in Fig. 5, but for 850-hPa $\theta_{e}$ anomalies (K, shaded warm colors for positive anomalies), composite 850-hPa $\theta_{e}\left(\mathrm{~K}\right.$, solid contours), and statistical significance of the $850-\mathrm{hPa} \theta_{e}$ anomalies.

example in Fig. 3. The trajectories in types A-C (Figs. $17 \mathrm{a}-\mathrm{c})$ show the importance of the Atlantic Ocean as a moisture source, as almost all parcels in type $\mathrm{A}$ and all parcels in types $\mathrm{B}$ and $\mathrm{C}$ originate off the U.S. east coast and ascend rapidly as they approach Montreal. In addition, types A-C show air parcels moving anticyclonically around the composite mean ridge seen in all three types
(Figs. 5-7 and 9-11). The type D trajectories (Fig. 17d) are markedly different from any other type. Some parcels do appear to originate in the Gulf of Mexico and ascend slightly over time, but the majority of parcels take a cyclonic path from the midwestern United States and are predominantly sinking, before ascending gently in the $24-36 \mathrm{~h}$ before $t=0 \mathrm{~h}$. This corresponds with the 


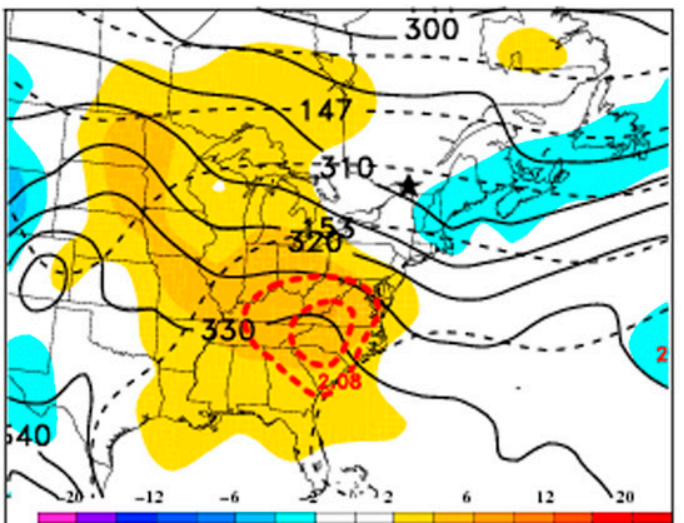

a) $t=-48 h$
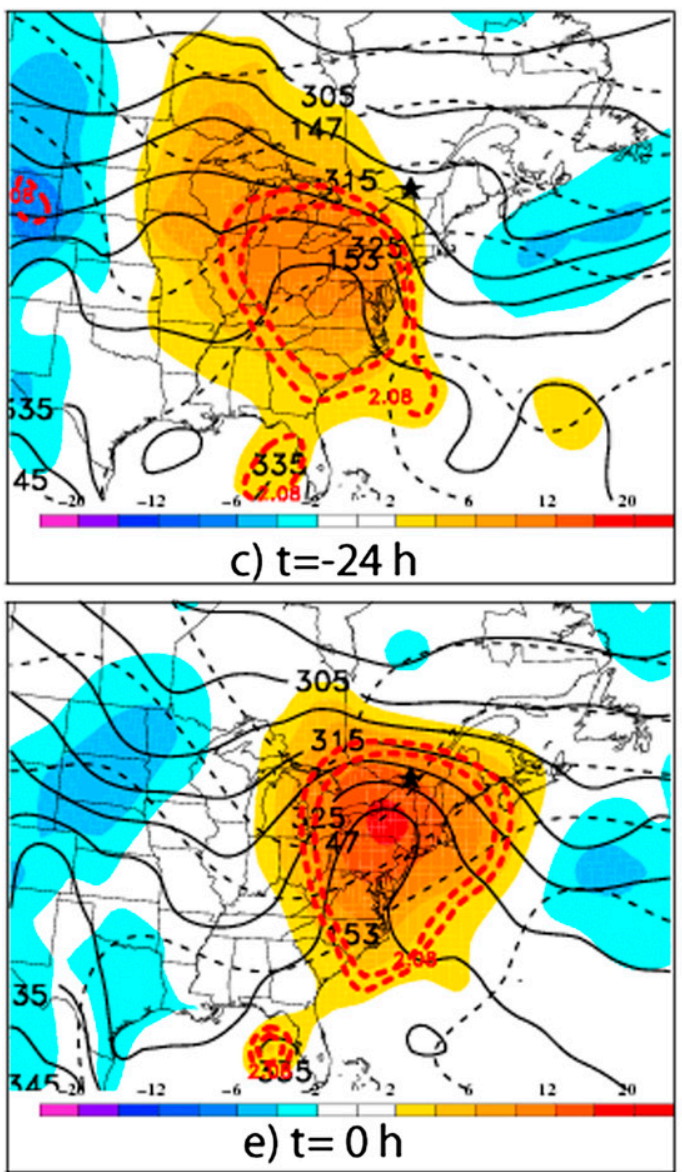
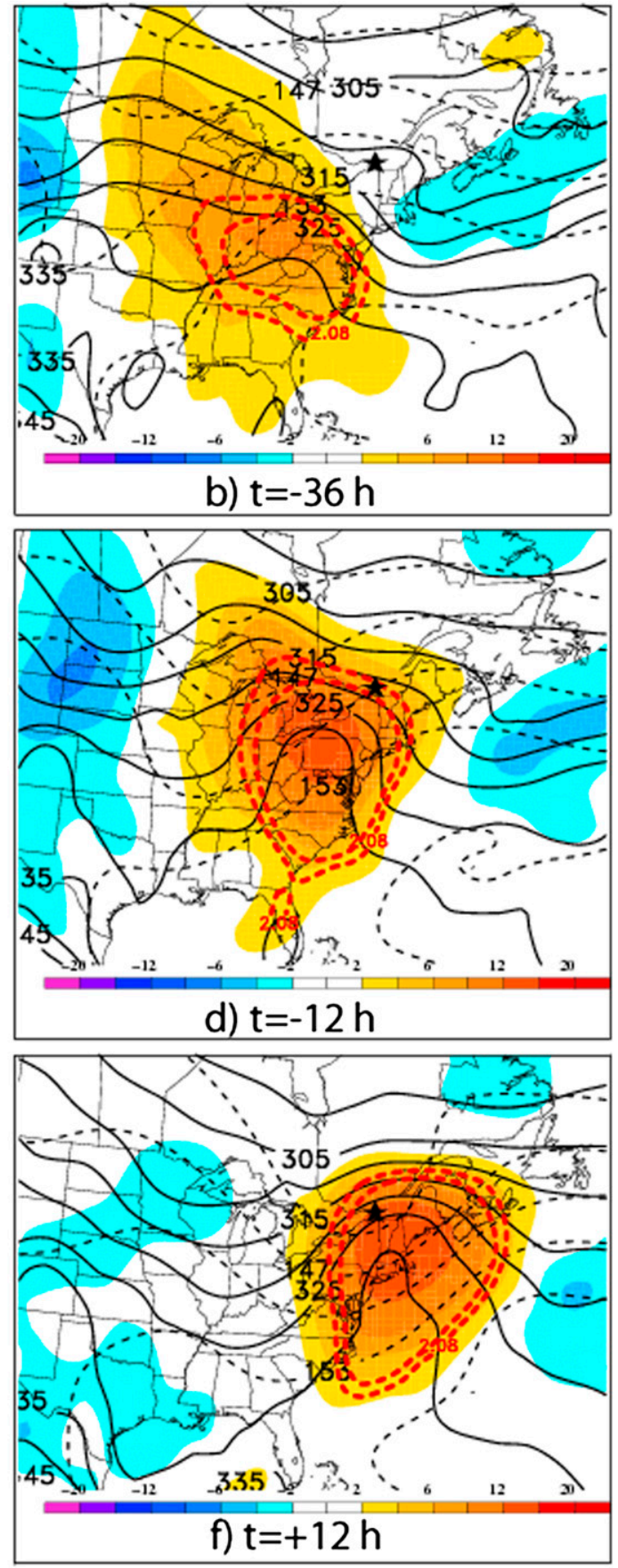

FIG. 14. As in Fig. 13, but for all type B.

observation of an in situ ridge (Figs. 8 and 12) over eastern North America, with weak cyclonic disturbances traversing the mean ridge environment.

\section{e. Composite soundings}

Composite soundings are shown at $t=0 \mathrm{~h}$ for types A-D in Fig. 18. Type A (Fig. 18a) exhibits the lowest tropopause of any type (approximately $250 \mathrm{hPa}$ ), suggesting the presence of a nearby upper-level trough. Type A also features a strongly veering wind profile in the lowest $200 \mathrm{hPa}$, in accordance with the $\mathbf{Q}_{s}$ convergence ahead of the MSLP cyclone (Fig. 9).

The tropopause levels in types B-D (Figs. 18a,b) are relatively high (near $200 \mathrm{hPa}$ ), corroborating the precursor 

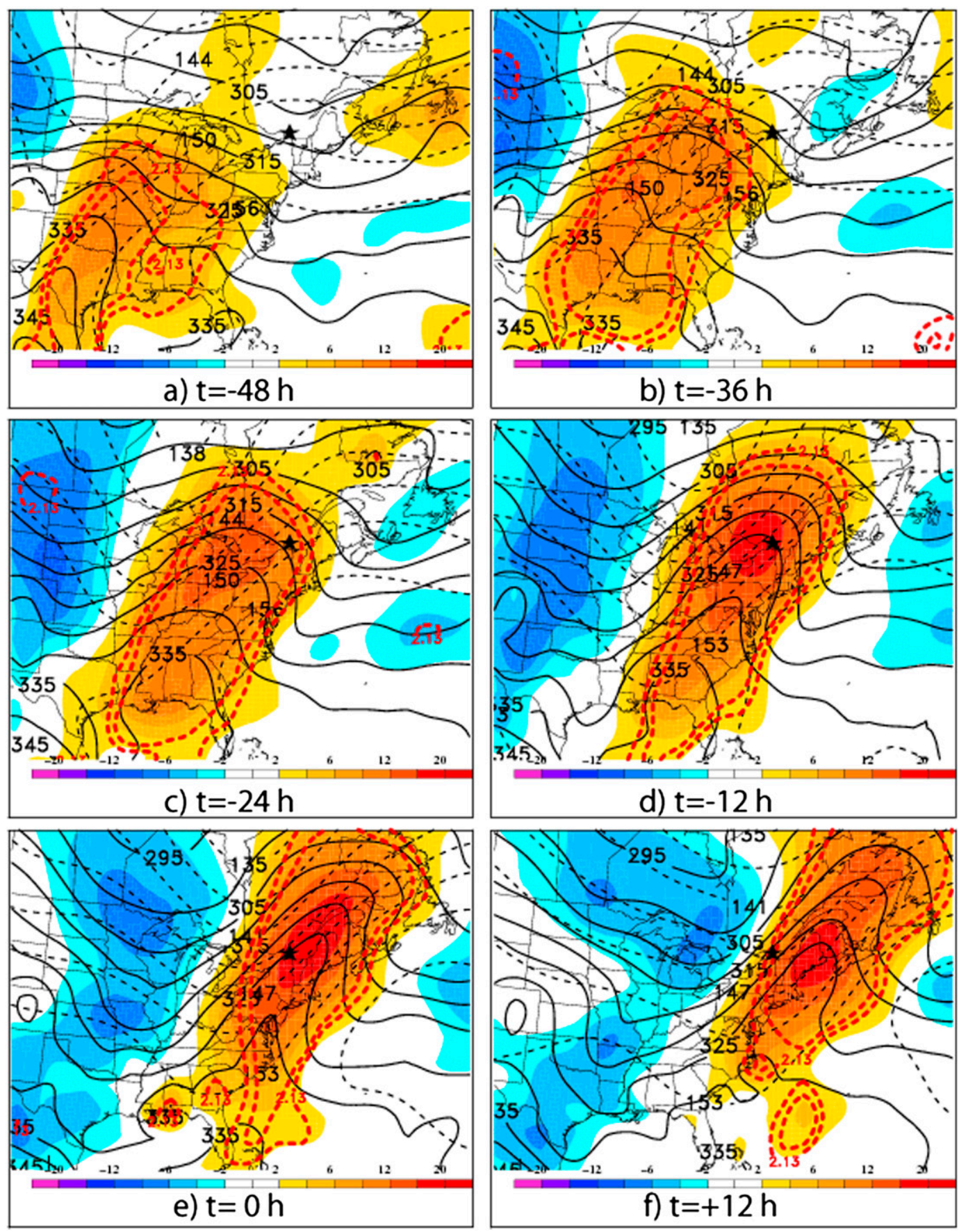

FIG. 15. As in Fig. 13, but for all type C.

anomalous upper-level ridges and warm air masses observed in the Montreal region (Figs. 6-8 and 14-16). In type B (Fig. 18a), both lower-tropospheric veering and a temperature inversion are evident above $925 \mathrm{hPa}$, consistent with a warm frontal passage. Only slight veering is evident in type C (Fig. 18b), while the nearsurface unstable layer is consistent with conditions just prior to a cold frontal passage (Fig. 18b). In addition, the composite surface temperature and dewpoint are considerably warmer in type C (Fig. 18b) than in types A and B (Fig. 18a).

Finally, type D (Fig. 18b) features the warmest composite surface temperature and dewpoint of any type, consistent with the presence of an anomalously warm, 


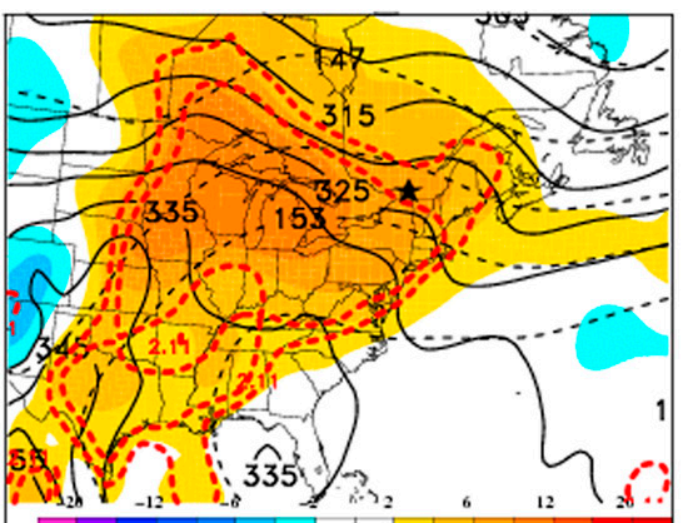

a) $t=-48 \mathrm{~h}$
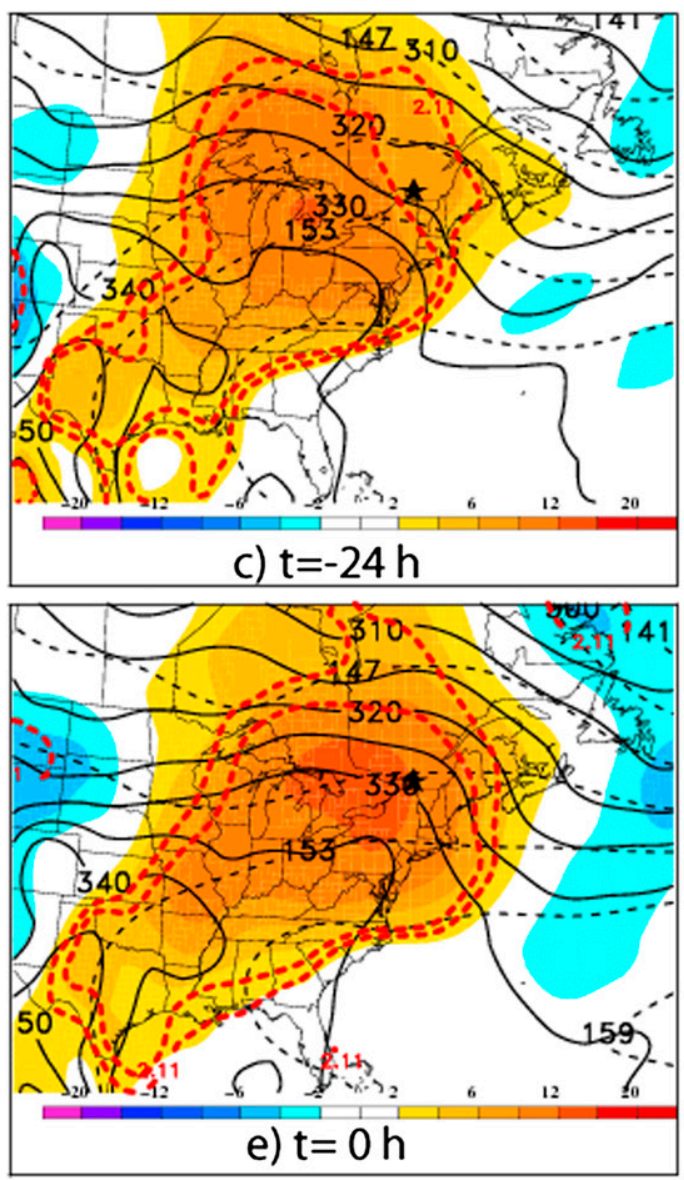
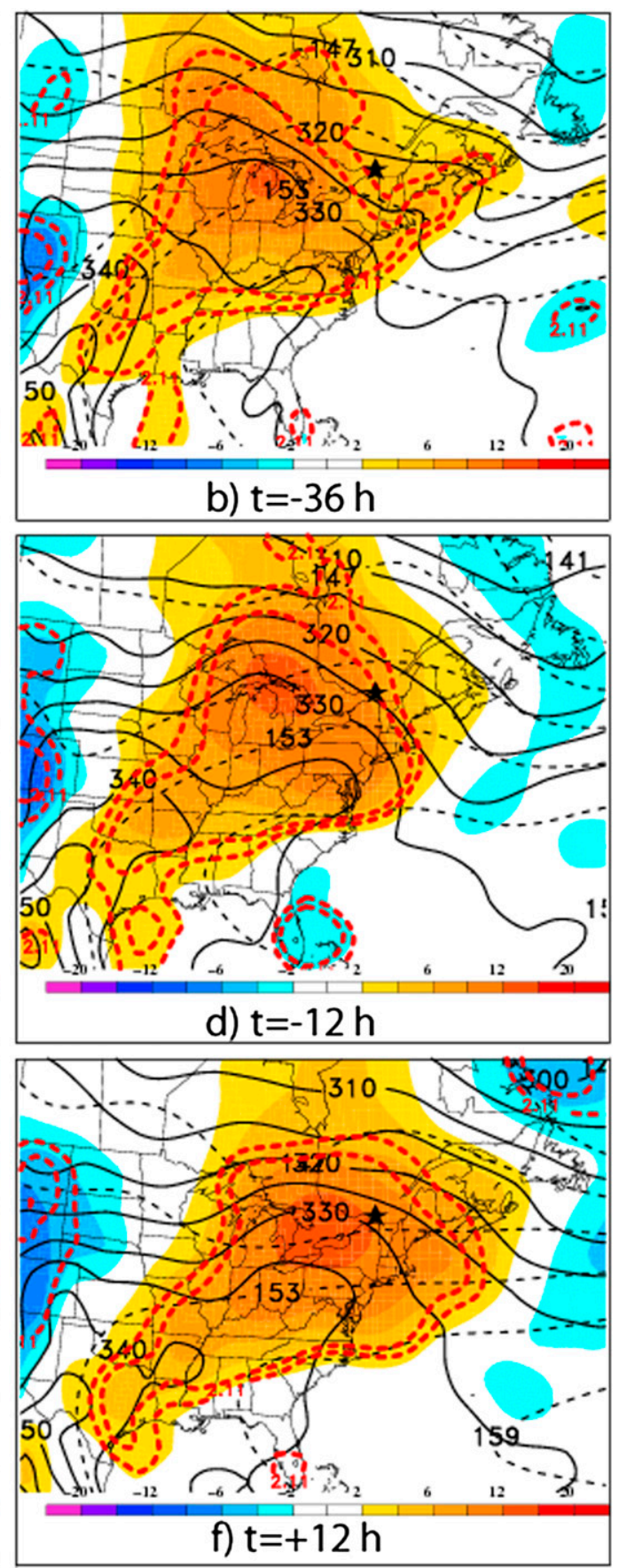

FIG. 16. As in Fig. 13, but for all type D.

humid air mass in eastern North America (Fig. 16). Steep low-level lapse rates are evident in both types C and D (Fig. 18b), which suggest that these types might be more conducive to convection than types A and B (Fig. 18a). In addition, diagnostics of convective parameters (not shown; e.g., $\mathrm{K}$ index, bulk wind shear) suggest that types $\mathrm{C}$ and $\mathrm{D}$ feature the most unstable environments with sufficiently high bulk wind shear to produce organized convection. Specially, type $\mathrm{C}$ exhibits a $\mathrm{K}$ index of $>25$ and $70+\mathrm{kt}\left(1 \mathrm{kt}=0.51 \mathrm{~m} \mathrm{~s}^{-1}\right)$ of $1000-500-\mathrm{hPa}$ wind shear at $t=0 \mathrm{~h}$ as the cold front approaches, while in type $\mathrm{D}$ the $\mathrm{K}$ index is $>25$ from $t=-12$ to $+12 \mathrm{~h}$, inclusive, with bulk shear values $(40+\mathrm{kt})$ supportive of organized convection. With regard to type D cases, Fig. 18b 
NOAA HYSPLIT MODEL

a) Backward trajectories ending at 0600 UTC 06 Oct 95 CDC1 Meteorological Data

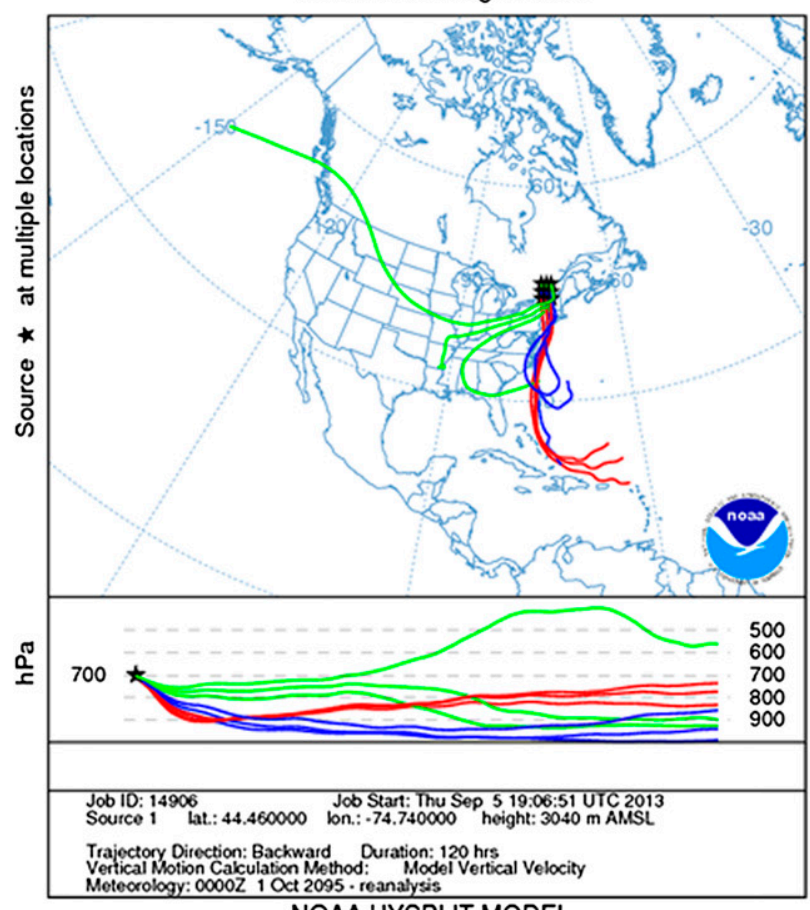

NOAA HYSPLIT MODEL UTC 08 Nov 96 CDC1 Meteorological Data

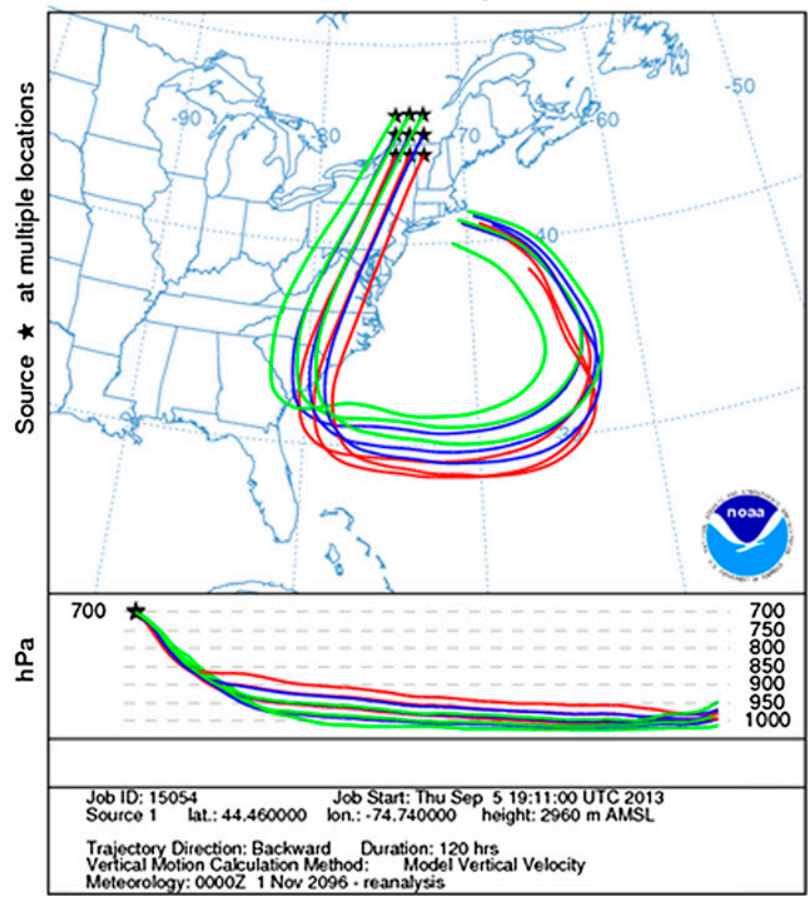

NOAA HYSPLIT MODEL

b) Backward trajectories ending at 1200 UTC 01 Nov 94 CDC1 Meteorological Data

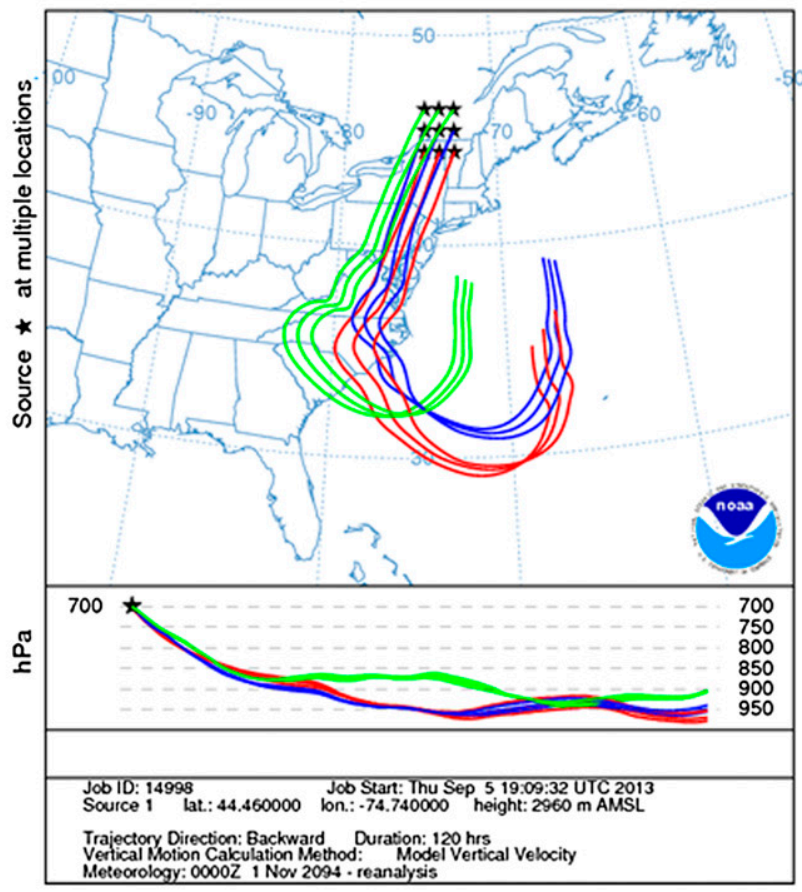

NOAA HYSPLIT MODEL

d) Backward trajectories ending at 0000 UTC 31 Jul 04 CDC1 Meteorological Data

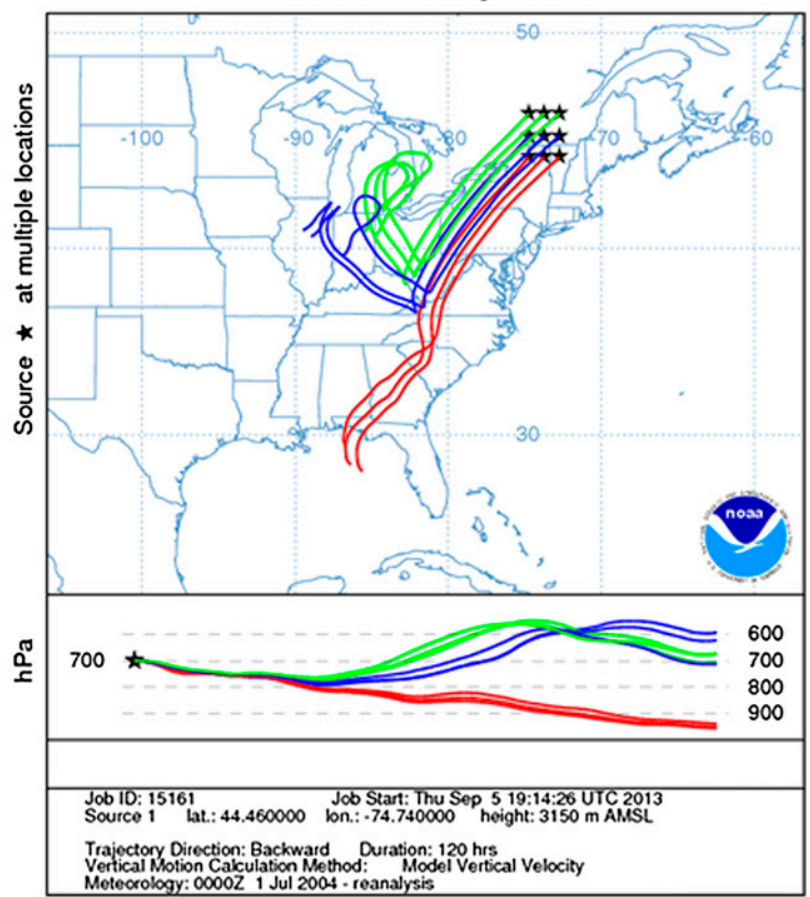

FIG. 17. For the sample cases in Fig. 3, nine 120-h backward air parcel trajectories from the NOAA HYSPLIT model starting at $t=0 \mathrm{~h}$ with the ending points at $700 \mathrm{hPa}$ (marked with black stars) for types (a) A, (b) B, (c) C, and (d) D. Ending points are distributed within a $2^{\circ}$ latitude $\times 2^{\circ}$ longitude box centered on CYUL. Note that the map projections are slightly different in each panel. 


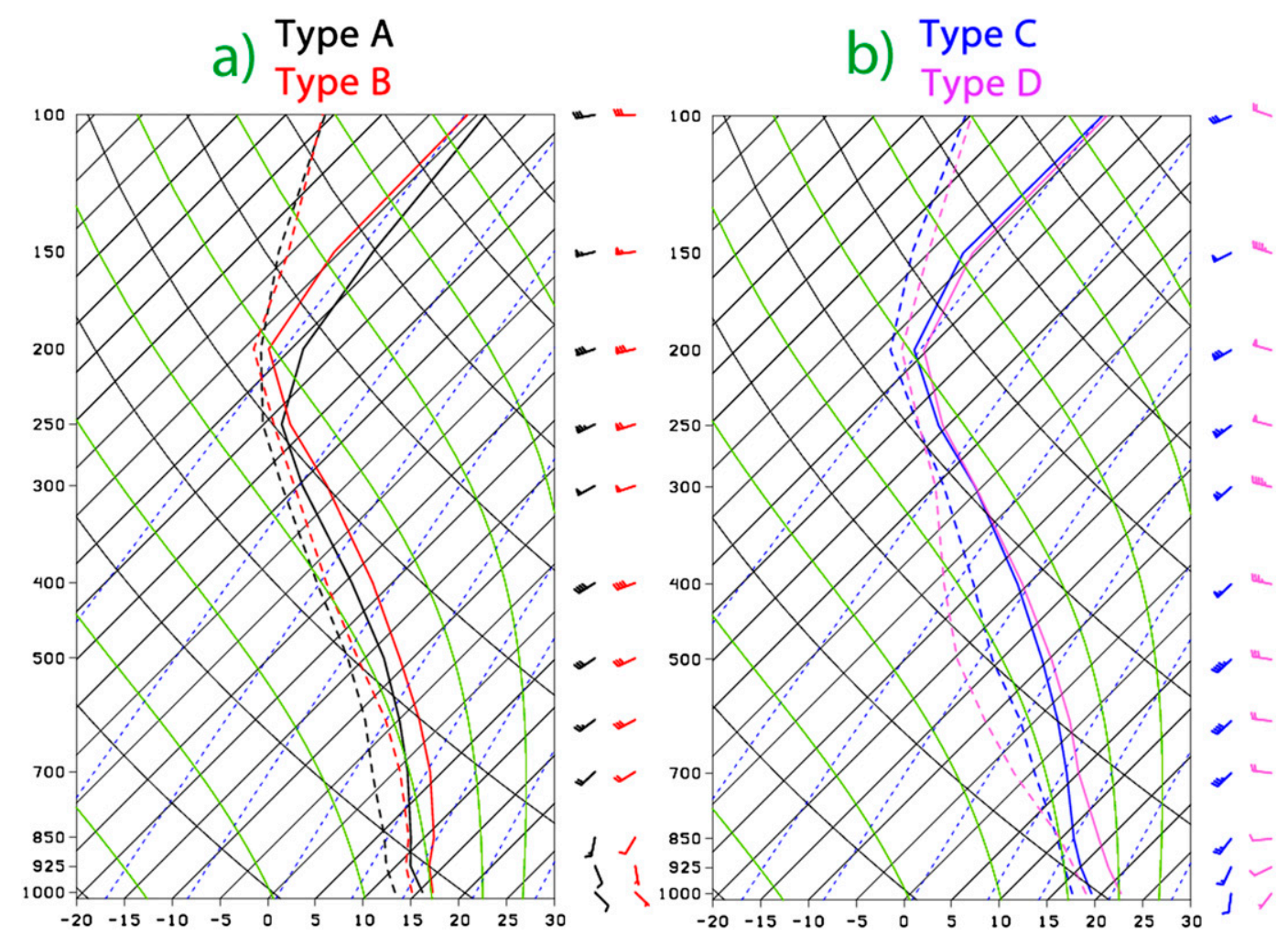

FIG. 18. Composite soundings at $t=0 \mathrm{~h}$ for type (a) A (black), B (red) and (b) C (blue) and D (purple). The solid line in each sounding is temperature $\left({ }^{\circ} \mathrm{C}\right)$ and the dashed line denotes dewpoint temperature $\left({ }^{\circ} \mathrm{C}\right)$.

shows a slightly veering profile. Therefore, in summary, type $\mathrm{D}$ events feature a weak short-wave trough moving through the long-wave ridge environment (Fig. 16), which acts in combination with an air mass conducive to convection (i.e., large instability, shear), resulting in heavy precipitation.

\section{Concluding discussion and future work}

We identify 1663 warm-season (June-November) synoptically independent precipitation events from 1979 to 2008. Events are partitioned by intensity category using percentiles. June-November was chosen to correspond with the Atlantic tropical cyclone season. Of the 166 heavy (top $10 \%$ ) precipitation events at CYUL, only 8 were directly associated with an ET (Table 3), based on National Hurricane Center (NHC) best-track data. However, as Milrad et al. (2009a, 2013) pointed out, this does not include events where PREs (e.g., Galarneau et al. 2010) or remnant TC precipitation affected Montreal, despite NHC having stopped tracking the system; the remnants of Hurricane Katrina (2005; Milrad et al. 2009a) are an example of such a case.

We complete a manual synoptic typing of the 166 heavy events, utilizing $\mathbf{Q}_{s}$ and $\mathbf{Q}_{n}$ convergence; four types are recognized (Table 2). All four event types feature a precursor synoptic-scale anticyclone near or just downstream of CYUL (Figs. 9-12), which helps in establishing southerly high- $\theta_{e}$ air advection. In types A-C, air parcels from the Atlantic Ocean are clearly transported anticyclonically as they ascend and move toward Montreal (Figs. 17a-c). These findings add a new wrinkle to the recent study of Pfahl and Wernli (2012), who found that a high percentage of extreme precipitation events are directly related to cyclones. Specifically, our results combined with past results at different locations (e.g., Sisson and Gyakum 2004; Milrad et al. 2009b, 2010b) strongly suggest that anticyclones may also be a crucial contributor to heavy precipitation events, by helping to change the characteristics of the existing air mass (i.e., a priori transporting high $\theta_{e}$ air into the region of interest).

Type A $(n=103)$ is found to be predominantly cyclonerelated. Type A cases feature a precursor trough over the northern plains and a precursor ridge downstream of Montreal (Fig. 5). The typical type A MSLP cyclone tracks either (a) through the SLRV or (b) along the New England coast (Fig. 9). In both tracks, large values of $\mathbf{Q}_{s}$ convergence indicate strong synoptic-scale QG forcing for ascent. 
Types B and C are both frontal related, with important distinguishing features between them. In type B, the anomalous downstream ridge (Figs. 6 and 10) is a more prominent player relative to the upstream trough than in type A. Composite $\mathbf{Q}_{n}$ convergence far exceeds composite $\mathbf{Q}_{s}$ convergence, and 1000-500-hPa thicknesses increase over time, suggesting the importance of mesoscale QG forcing for ascent as the warm front moves through Montreal. Anomalously high- $\theta_{e}$ air (Fig. 14) is originally pooled in the Appalachians before being advected toward Montreal. The composite sounding (Fig. 18a) shows a near-surface temperature inversion typical of a warm frontal passage.

In type C events, statistically significant 500 -hPa height, MSLP, and $\theta_{e}$ anomalies are evident the earliest (up to 3 days prior) and are the most amplified of any type (Figs. 7, 11, and 15). An amplified trough-ridge couplet (and associated $\mathbf{Q}_{s}$ convergence) tracks to the north of Montreal (Figs. 7 and 11), and long-lived high- $\theta_{e}$ air advection is observed ahead of the cold front (Fig. 15). Accordingly, large values of composite $\mathbf{Q}_{n}$ convergence are observed at Montreal (Fig. 11). The composite sounding (Fig. 18b) also suggests steep low-level lapse rates and a relatively unstable atmosphere. Composite mean $\theta_{e}$, surface temperature, and surface dewpoint values are substantially higher in type $C$ than in types $A$ and $\mathrm{B}$, as are convective parameters such as the $\mathrm{K}$ index and bulk wind shear (not shown). Therefore, although type C (and to a lesser extent type B) events are associated with primarily frontal forcing for ascent, a warmer, more humid air mass acts to compensate (Gyakum 2008). As such, there is generally no systematic preference for higher precipitation amounts in any type (Fig. 4), although slow-moving cases of type $\mathrm{C}$ (i.e., stationary fronts) have occasionally resulted in the highest event totals (e.g., Durnford 2001).

Type D events are characterized by (a) no obvious synoptic-scale or mesoscale QG ascent-forcing mechanism (Figs. 8 and 12), (b) a quasi-stationary anomalous 500-hPa ridge over Montreal (Fig. 8), and (c) an in situ anomalously warm, humid (high $\theta_{e}$ ) air mass associated with southerly flow on the western side of the Bermuda high (Fig. 16). Unlike the other three types, the synopticscale features in type $\mathrm{D}$ are not very transient. The warm humid air mass over Montreal is relatively unstable (Fig. 18b), such that the smallest of triggers would likely be conducive to convection, as evidenced by sufficient $\mathrm{K}$ index (the largest of any type) and bulk wind shear values (not shown). We suggest that since convection cannot occur without an ascent mechanism, such a trigger may be provided by what Galarneau and Bosart (2005) termed ridge rollers, or short-wave vorticity maxima that move around the periphery of a long-wave ridge.
The composite type D 500-hPa height pattern (Fig. 8), 500-hPa spaghetti plots (not shown), flattening of the 700-hPa ridge (Fig. 16), and cyclonic air parcel trajectories (Fig. 17d) are all suggestive of this.

Briefly putting our results within the context of past work, type A events most closely resemble the "synoptic" and "extratropical cyclone" events recognized by Maddox et al. (1979) and La Penta et al. (1995), respectively. By partitioning warm and cold frontal events into two different types (types B and C, respectively), we differ slightly from Maddox et al. (1979) and La Penta et al. (1995), who identified frontal and stationary cold front categories, respectively. Specifically, our type C composite results show how cold frontal events feature much larger meridional height and moisture anomalies than warm frontal events (type B), in addition to lower static stability. Finally, Schumacher and Johnson (2006) found that most of the heaviest rainfall events in the warm season were associated with MCSs, which our results do not necessary contradict. To that end, our study encompasses both meteorological summer and autumn (June-November) in order to account for the Atlantic basin tropical cyclone season focusing on a location at a higher latitude (southern Canada).

Future work will be primarily aimed toward testing and quantifying the importance of the downstream anticyclone for heavy precipitation events. In addition, a formal elucidation of the synoptic-scale differences between different event intensity classes (e.g., heavy versus moderate) is warranted. Finally, an examination of the predictability of each of our synoptic types in numerical models would provide additional insight to the operational forecaster.

Acknowledgments. Thanks to Environment Canada and Ouranos for providing access to 6-hourly precipitation data, and the National Centers for Environmental Prediction (NCEP) and the National Climatic Data Center (NCDC) for providing access to the reanalysis datasets. This study was based in part on Giselle Dookhie's M.S. thesis at McGill University, and was funded in part by National Science and Engineering Research Council (NSERC) Discovery and CCAR (Climate Change and Atmospheric Research) grants, as well as Ouranos. Finally, we thank the two anonymous reviewers for their extremely constructive comments toward revising this manuscript.

\section{REFERENCES}

Bluestein, H., 1992: Principles of Kinematics and Dynamics. Vol. 1, Synoptic-Dynamic Meteorology in Midlatitudes, Oxford University Press, $431 \mathrm{pp}$. 
Bosart, L. F., 1981: The Presidents' Day snowstorm of 18-19 February 1979: A subsynoptic-scale event. Mon. Wea. Rev., 109, 1542-1566.

—, G. J. Hakim, K. R. Tyle, M. A. Bedrick, W. E. Bracken, M. J. Dickinson, and D. M. Schultz, 1996: Large-scale antecedent conditions associated with the 12-14 March 1993 cyclone ("Superstorm '93") over eastern North America. Mon. Wea. Rev., 124, 1865-1891.

Dookhie, G., 2011: Dynamics of heavy warm-season precipitation events in Montreal. M.S. thesis, Dept. of Atmospheric and Oceanic Sciences, McGill University, 93 pp.

Doswell, C. A., III, H. E. Brooks, and R. A. Maddox, 1996: Flash flood forecasting: An ingredients-based methodology. Wea Forecasting, 11, 560-581.

Draxler, R. R., and G. D. Rolph, cited 2012: HYSPLIT - Hybrid Single-Particle Lagrangian Integrated Trajectory model. NOAA/ Air Resources Laboratory. [Available online at http://ready.arl. noaa.gov/HYSPLIT.php.]

Durnford, D. A., 2001: An analysis of Montreal's record-breaking heavy rainfall event of 8-9 November 1996, and a comparison with its best analogue. M.S. thesis, Dept. of Atmospheric and Oceanic Sciences, McGill University, 122 pp.

Fritsch, J. M., and R. E. Carbone, 2004: Improving quantitative precipitation forecasts in the warm season: A USWRP research and development strategy. Bull. Amer. Meteor. Soc., 85, 955-965.

Funk, T. W., 1991: Forecasting techniques utilized by the forecast branch of the National Meteorological Center during a major convective rainfall event. Wea. Forecasting, 6, 548-564.

Galarneau, T. J., Jr., and L. F. Bosart, 2005: Ridge rollers: Mesoscale disturbances on the periphery of cutoff anticyclones. Preprints, 21st Conf. on Weather Analysis and Forecasting/17th Conf. on Numerical Weather Prediction, Washington, DC, Amer. Meteor. Soc., 3.2. [Available online at https://ams. confex.com/ams/pdfpapers/94414.pdf.]

- _ — , and R. S. Schumacher, 2010: Predecessor rain events ahead of tropical cyclones. Mon. Wea. Rev., 138, 3272-3297.

Gyakum, J. R., 1991: Meteorological precursors to the explosive intensification of the $Q E I I$ storm. Mon. Wea. Rev., 119, 11051131.

— 2008: The application of Fred Sanders' teaching to current research on extreme cold-season precipitation events in the Saint Lawrence River valley region. Synoptic-Dynamic $M e$ teorology and Weather Analysis and Forecasting: A Tribute to Fred Sanders, Meteor. Monogr., No. 55, Amer. Meteor. Soc. 241-250.

— slow growth/rapid cyclogenesis during CASP II. Atmos.Ocean, 34, 17-50.

— a planetary-scale event. Mon. Wea. Rev., 129, 2983-2997.

_ D. Dhang, J. Witte, K. Thomas, and W. Wintels, 1996: CASP II and the Canadian cyclones during the 1989-92 cold seasons. Atmos.-Ocean, 34, 1-16.

_- E. Atallah, P. Sisson, M. Kimball, and A. Roberge, 2005: Warm season extreme quantitative precipitation forecasting for the Burlington, VT region. Preprints, 21st Conf. on Weather Analysis and Forecasting/17th Conf. on Numerical Weather Prediction, Washington, DC, Amer. Meteor. Soc., P1.20. [Available online at https://ams.confex.com/ams/ pdfpapers/94807.pdf.]

Hart, R., and J. Evans, 2001: A climatology of the extratropical transition of Atlantic tropical cyclones. J. Climate, 14, 547-564.
Heideman, K. F., and J. M. Fritsch, 1988: Forcing mechanisms and other characteristics of significant summertime precipitation. Wea. Forecasting, 3, 115-130.

Hoskins, B. J., I. Draghici, and H. C. Davies, 1978: A new look at the omega equation. Quart. J. Roy. Meteor. Soc., 104, 31-38.

Kalnay, E., and Coauthors, 1996: The NCEP/NCAR 40-Year Reanalysis Project. Bull. Amer. Meteor. Soc., 77, 437-471.

Kanamitsu, M., W. Ebisuzaki, J. Woollen, S.-K. Yang, J. J. Hnilo, M. Fiorino, and G. L. Potter, 2002: NCEP-DOE AMIP-II Reanalysis (R-2). Bull. Amer. Meteor. Soc., 83, 1631-1643.

Keyser, D., M. J. Reeder, and R. J. Reed, 1988: A generalization of Petterssen's frontogenesis function and its relation to the forcing of vertical motion. Mon. Wea. Rev., 116, 762-780.

Koch, S., M. desJardins, and P. Kocin, 1983: An interactive Barnes objective map analysis scheme for use with satellite and conventional data. J. Climate Appl. Meteor., 22, 1487-1503.

Konrad, C. E., II, 1997: Synoptic-scale features associated with warm season heavy rainfall over the interior southeastern United States. Wea. Forecasting, 12, 557-571.

Lackmann, G. M., and J. R. Gyakum, 1996: The synoptic and planetary-scale signatures over the Mackenzie River basin. Atmos.-Ocean, 34, 647-674.

$\longrightarrow$, and — 1999: Heavy cold-season precipitation in the northwestern United States: Synoptic climatology and an analysis of the flood of 17-18 January 1986. Wea. Forecasting, 14, 687-700.

Ladd, J. W., and D. M. Driscoll, 1980: A comparison of objective and subjective means of weather typing: An example from west Texas. J. Appl. Meteor., 19, 691-704.

LaPenta, K. D., and Coauthors, 1995: The challenge of forecasting heavy rain and flooding throughout the Eastern Region of the National Weather Service. Part I: Characteristics and events. Wea. Forecasting, 10, 78-90.

Maddox, R. A., C. F. Chappell, and L. R. Hoxit, 1979: Synoptic and mesoscale aspects of flash flood events. Bull. Amer. Meteor. Soc., 60, 115-123.

Martin, J. E., 2006a: The role of shearwise and transverse quasigeostrophic vertical motions in the midlatitude cyclone life cycle. Mon. Wea. Rev., 134, 1174-1193.

_ 2006b: Mid-Latitude Atmospheric Dynamics. John Wiley and Sons, $324 \mathrm{pp}$.

Martius, O., C. Schwierz, and H. C. Davies, 2008: Far-upstream precursors of heavy precipitation events on the Alpine southside. Quart. J. Roy. Meteor. Soc., 134, 417-428.

Mekis, E., and W. D. Hogg, 1999: Rehabilitation and analysis of Canadian daily precipitation time series. Atmos.-Ocean, 37, $53-85$.

Mesinger, F., and Coauthors, 2006: North American Regional Reanalysis. Bull. Amer. Meteor. Soc., 87, 343-360.

Milrad, S. M., E. H. Atallah, and J. R. Gyakum, 2009a: Dynamical and precipitation structures of poleward-moving tropical cyclones in eastern Canada, 1979-2005. Mon. Wea. Rev., 137, 836-851.

$\longrightarrow,-$, and $\longrightarrow, 2009 \mathrm{~b}$ : Synoptic-scale characteristics and precursors of cool-season precipitation events at St John's, Newfoundland, 1979-2005. Wea. Forecasting, 24, 667-689.

,$- \ldots$, and 2010a: A diagnostic examination of consecutive extreme cool-season precipitation events at St. John's, Newfoundland, in December 2008. Wea. Forecasting, 25, 997-1026.

,-- , and $-2010 \mathrm{~b}$ : Synoptic typing of extreme coolseason precipitation events at St. John's, Newfoundland, 1979-2005. Wea. Forecasting, 25, 562-586. 
,$- \ldots$, and -2013 : Precipitation modulation by the Saint Lawrence River valley in association with transitioning tropical cyclones. Wea. Forecasting, 28, 331-352.

Moore, B. J., L. F. Bosart, and D. Keyser, 2013: Synoptic-scale environments of predecessor rain events occurring east of the Rocky Mountains in association with Atlantic basin tropical cyclones. Mon. Wea. Rev., 141, 1022-1047.

Muller, R. A., 1977: A synoptic climatology for environmental baseline analysis: New Orleans. J. Appl. Meteor., 16, 20-33.

— potential at Shreveport, Louisiana. J. Climate Appl. Meteor., 24, 293-301.

Ouranos, 2012: Catalogue available datasets through DAI (Data Access Integration). [Available online at http://loki.ouranos. $\mathrm{ca} / \mathrm{DAI} /$.

Overland, J. E., and T. R. Hiester, 1980: Development of a synoptic climatology for the northeast Gulf of Alaska. J. Appl. Meteor., 19, 1-14.

Pfahl, S., and H. Wernli, 2012: Quantifying the relevance of cyclones for precipitation extremes. J. Climate, 25, 6770-6780.

Ralph, F. M., P. J. Neiman, and G. A. Wick, 2004: Satellite and CALJET aircraft observations of atmospheric rivers over the eastern North Pacific Ocean during the winter of 1997/98. Mon. Wea. Rev., 132, 1721-1745.

Roberge, A., J. Gyakum, and E. Atallah, 2009: Analysis of intense poleward water vapor transports into high latitudes of western North America. Wea. Forecasting, 24, 1732-1747.

Roebber, P. J., and L. F. Bosart, 1998: The sensitivity of precipitation to circulation details. Part I: An analysis of regional analogs. Mon. Wea. Rev., 126, 437-455.

_ scale structure of the 1998 ice storm. Mon. Wea. Rev., 131, 27-50.

Saha, S., and Coauthors, 2010: The NCEP Climate Forecast System Reanalysis. Bull. Amer. Meteor. Soc., 91, 1015-1057.

Schumacher, R. S., and R. H. Johnson, 2005: Organization and environmental properties of extreme-rain-producing mesoscale convective systems. Mon. Wea. Rev., 133, 961-976.
— , and - 2006: Characteristics of U.S. extreme rain events during 1999-2003. Wea. Forecasting, 21, 69-85.

— rainfall in a midlatitude warm-season flash flood. Mon. Wea. Rev., 136, 3964-3986.

— , and — 2009: Quasi-stationary, extreme-rain-producing convective systems associated with midlevel cyclonic circulations. Wea. Forecasting, 24, 555-574.

_ , and T. J. Galarneau Jr., 2012: Moisture transport into midlatitudes ahead of recurving tropical cyclones and its relevance in two predecessor rain events. Mon. Wea. Rev., 140, 1810-1827.

Sisson, P. A., and J. R. Gyakum, 2004: Synoptic-scale precursors to significant cold-season precipitation events in Burlington, Vermont. Wea. Forecasting, 19, 841-854.

Stewart, R. E., and N. R. Donaldson, 1989: On the nature of rapidly deepening Canadian east coast winter storms. Atmos.-Ocean, 27, 87-107.

—, R. W. Shaw, and G. A. Isaac, 1987: Canadian Atlantic Storms Program: The meteorological field project. Bull. Amer. Meteor. Soc., 68, 338-345.

Stone, D. A., A. J. Weaver, and F. W. Zwiers, 2000: Trends in Canadian precipitation intensity. Atmos.-Ocean, 38, 321-347.

Szeto, K., W. Henson, R. Stewart, and G. Gascon, 2011: The catastrophic June 2002 prairie rainstorm. Atmos.-Ocean, 49, 380-395.

Warner, M. D., C. F. Mass, and E. P. Salathe Jr., 2012: Wintertime extreme precipitation events along the Pacific Northwest coast: Climatology and synoptic evolution. Mon. Wea. Rev., 140, 2021-2043.

Yagouti, A., G. Boulet, L. Vincent, L. Vescovi, and E. Mekis, 2008: Observed changes in daily temperature and precipitation indices for southern Québec, 1960-2005. Atmos.-Ocean, 46, 243-256.

Zishka, K. M., and P. J. Smith, 1980: The climatology of cyclones and anticyclones over North America and surrounding ocean environs for January and July, 1950-77. Mon. Wea. Rev., 108, 387-401. 